\title{
Three-Phase Four-Switch Converter for SPMS Generators Based on Model Predictive Current Control for Wave Energy Applications
}

\author{
Mohammad Ebrahim Zarei ${ }^{\circledR}$, Dionisio Ramírez ${ }^{\circledR}$, Senior Member; IEEE, Carlos Veganzones Nicolas, \\ and Jaime Rodríguez Arribas ${ }^{(0)}$
}

\begin{abstract}
This paper presents a model predictive current control (MPCC) for three-phase four-switch converters (IPPSC) comnected to surface permanent magnet synchronous generators (SPMS(;s) in oscillating water column (OWC) wave energy plants, that brings some benefits over the existing control methods used in this type of plants. The proposed MPCC for TPISC follows the current references with great accuracy; whereas the switching fiequency of the insulated-gate bipolar transistor (IF B P is fixed and low: This method minimizes the current reference tracking error, and its fast response makes it suitable for the power take-off sy:tems present in wave energy converters. Furthermore, the system features a fist capacitor voltage offset suppression control. The dynamic performance and the voltage offset control of the proposed strategy for TPISC feeding a SPMSC; is evaluated in the Simulink enviromment. Later, experimental studies are carried out on an 8.7 $\mathrm{kW}$ laboratory SPMS(; prototype. linally, the capability of the proposed method to harvest the maximum energy from irregular waves is assessed using an (OWC power plant emulator.
\end{abstract}

Index Terms Control system, emulation, oscillating water columu (OWC), predictive control, wave energy:

\section{INTRODUCTION}

O CEAN wave energy is one of the promising renewable energy sources which has attracted the attention of researchers, undergoing a fast develop during recent years [1]. Among the various types of wave energy converters (WEC), the oscillating water column (OWC) is the most improved technology and practical power-lakeoff (PTO) system [2], [3], see Fig. I. In this type of power plants, the pressure exerted by the waves inside a chamber produces an air tlow that drives an air turbine connected to an electric generator. The OWC can the installed onshore and of shore. However, the onshore is preferred due to its easier maintenance, robust structure, and easier grid conneclion [4].

This work was supported by the project number of DPI2017-88505-C 2-1-R of $\mathrm{l}+\mathrm{D}+\mathrm{i}$ projects of "Programa Estatal de Investigacion, Desarrollo $e$ Innovación Orientada a los Retos de la Sociedad" of Spain. Rec-ommended for publication by Associate Editor H. S. Krishnamoorthy. (Corresponding aurhor: Mohammend Ebrah im Zarei.)

The authors are with the Department of "Automática. Ingenieria Eléctrica y Electrónica e Informática Industrial," Escuela Técnica Superior de In-genieros Industriales, Universidad Politécnica de Madrid, Madrid 28006, Spain (e-mail: me.zarei@alumnos.upm.es; dionisio.ramirez@upm.es; carlos. veganzones@upm.es; jaime.rodriguez@upm.es).

Color versions of one or more of the figures in this paper are available online at hitp://ieexplore iee.org.
The generator of this PTO system has to operate under a variable speed regime in order to harvest the maximum energy from the very large airflow variations [5]. Squirrel cage and doubly fed induction generators (DFIG) [6], [7], as well as permanent magnet synchronous generators (PMSG) [8], have been used in OWC-based power plants.

One recent example of a large-scale commercial OWC wave plant was installed recently in Mutriku, Spain, and the obxained power is nowadays injected into the grid [9]. A variable speed DFIG fealuring vector controlled hack to back converters is used in this $296 \mathrm{~kW}$ wave power plant to obtain the maximum energy from the waves. However, in this OWC power plant was necessary to tune the proportional integrator (PI) controllers and to know well the model of the plant in order to control the system correcily [10]. [11]. Ocean waves are highly irregular and random so the airllow in the OWC chamber varies largely in few seconds. As a result, a robust speed control with a fast dynamic response is a vital part of the electrical generator control of any OWC plant. Consequently, nonlinear controls seem to be an appropriate solution. In [II], it is suggested to use a robust sliding mode control tor this power plant in Mutriku in order to achieve helter performances. Recently, the feasibility of employing a prediclive control for an OWC based on DFIG lor irregular waves has heen reported [12]. Although the performance of the system seems to he increased, the experimental results were not reported.

PMSG is another interesting choice for OWC power plants due to its higher efliciency, especially for low power systems, and also because of the possibility to eliminate the gearbox, which increases the reliability of the system [13]. In [14], a nonlinear hysteresis control is adopted for the PMSG-based PTO. The results are promising, but this solution deals with a high and variable switching frequency, which implies a poor current waveform or the need of using bigger lilters.

Another important matter that should be considered in WECs is that the system should continue working during some hardware laults such as the bieakdownof a switch, in order to prevent losing potential power from the waves or to keep the control of the buoy in the case of floating OWCs to assure the buoy survival under storm conditions.

The Ihree-phase tour-switch converter (TPFSC) is one of the lault-tolerant solutions that can be applied when one of the six switches or one of the converter legs is damaged. In this 


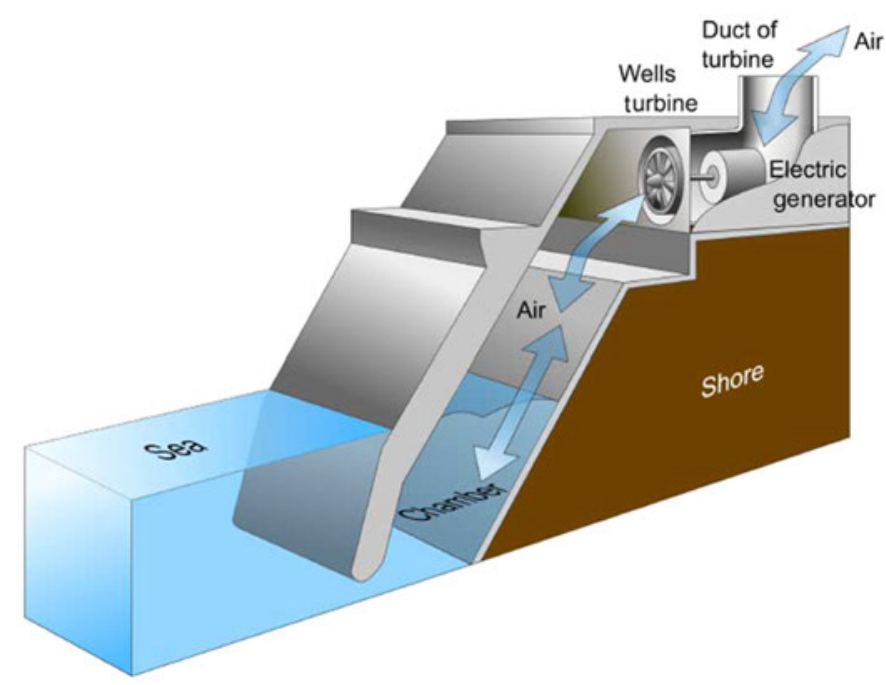

Fig. 1. Schematic representation of an OWC power plant.

case, the midpoint of the dc link should be connected to the faulty phase, while the rest four switches continue working [15], [16]. Although the converter can work with only four switches, unbalanced currents and high power ripples could appear in the system if the control is not properly designed for this fault situation [17].

TPFSC working as rectifiers, as shunt active filters, or feeding PMS motors, has been investigated during recent years [18]-[21]. In [21], a comprehensive torque ripple reduction is presented for TPFS feeding a PMSM, where a preferred space vector modulation (SVM) was proposed. The torque ripple that is induced by the voltage drop of the converter switches was eliminated by a compensation modulation strategy in the case of PMSM [22]. A hybrid SVM technique to reduce the torque ripple of a PMSM by using equivalent zero vectors is presented in [23]. This strategy determines the voltage sector location from the stator current position. In these last methods, the scope was focused on the modulation, while the current control strategy was not reported.

A predictive direct torque control for TPFS inverter was introduced to drive an induction machine in [24]. In this strategy, only one voltage vector that minimizes a cost function was employed at every switching period. Although the voltage deviation suppression was also included in the cost function using a weighting factor, the value of the corresponding factor had a big influence on the control, to the extent that the performance of the machine was deteriorated. Besides, the switching frequency was variable and the torque ripple was high. A model predictive current control (MPCC) for PMSM is presented in [25], introducing a four sectors division and a virtual duty cycle. According to the sector, one active voltage vector and the determined virtual duty cycle are employed. The effect of each voltage vector on the voltage deviation is studied in [26]. In order to remove the voltage offsets, it is necessary to extract the mean value of the capacitors which is usually done by using notch or low-pass filters [23], [26], [27]. This method was adopted in most of the research works to overcome the voltage offset. However, in this technique, when the speed of the machine is low, the results are not good, and it presents a big delay when extracting the mean value.

To the best knowledge of the authors, TPFSC connected to SPMSG for wave energy applications has not been reported. This is an important case, since the inherent irregular waves can make the dc voltage offset to have big values if a fast offset compensation strategy is not adopted, especially during the low rotational speeds. In this case, one of the midpoint capacitor voltages could reach zero volts, while the entire dc-link voltage is applied to the other capacitor, which could carry the breakdown of this capacitor. Additionally, a big offset in the capacitor voltages will prevent a good performance of the system. Consequently, due to the aforementioned reasons, the proposed control for the TPFSC of the SPMSG and for the capacitor voltage offset should have a fast dynamic response.

In this paper, a simple and effective MPCC for the three-phase four-switch machine-side converter (MSC) of the SPMSG oriented for OWC is presented. It is capable of performing highly dynamic speed control and features fixed switching frequency. In this method, only two sector divisions are defined, and three voltage vectors are applied at every switching period without using stator voltage sector location. Moreover, a fast response offset control is introduced in an outer layer of the predictive control without including it in the cost function. The capacitor voltage deviations are quickly suppressed without using any filter. It altogether makes the power plant capable of working properly despite having to deal with large variations of the airflow in the OWC chamber and, as a result, in the incoming energy.

This paper is organized as follows. The proposed MPCC with a fixed switching frequency feature for the TPFSC connected to SPMSG is presented in Section II. In this section, the proposed three voltage vector sequences and the voltage offset control are explained, while the effects of the vectors on the duration times are investigated. In Section III, the OWC-based power plant emulator and the method to extract the maximum energy from the OWC are explained. The simulation results in order to show the dynamic performance of the proposed predictive control and the effectiveness of the voltage offset elimination control are conducted in Section IV. Some of the many experimental tests intended to evaluate the dynamic response and the steadystate performance for an $8.7 \mathrm{~kW}$ SPMSG have been included in Section V. Furthermore, the TPFSC and the offset control were tested using an OWC power plant emulator with irregular waves in order to check the performances of the proposed method. Finally, the conclusions of this paper are presented in Section VI.

\section{Model Predictive CuRRENT CONTROL FOR THE SPMSG WHEN FED BY TPFSC}

The proposed fault-tolerant topology for the MSC of an SPMSG is shown in Fig. 2. In this topology, when a semiconductor open-circuit or short-circuit fault is detected and located, the faulty leg will be isolated and then by trigging the corresponding anti-parallel thyristors or triacs the faulty phase will 


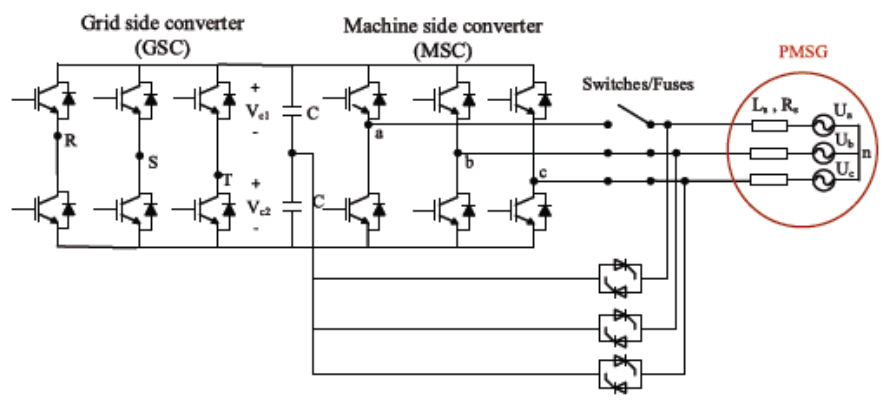

Fig. 2. Fault-tolerant topology schematic for the machine-side converter of a SPMSG.

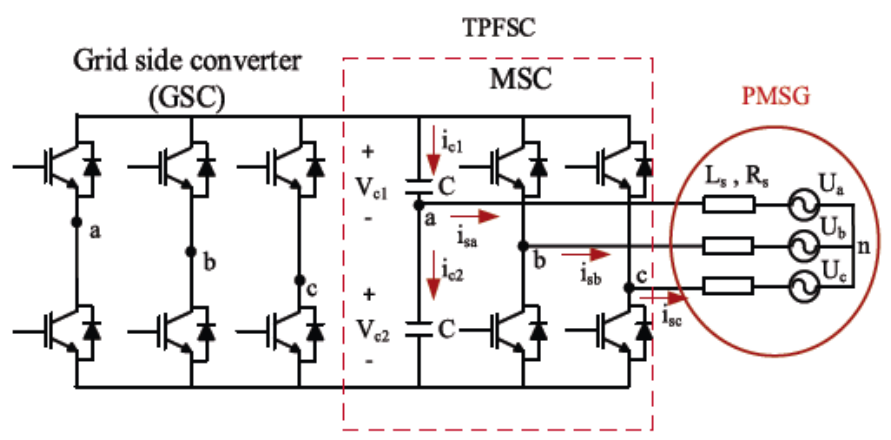

Fig. 3. Structure of a TPFSC connected to a SPMSG.

be connected to the midpoint of the dc bus as shown in Fig. 2. The semiconductor open-circuit and short-circuit faults can be diagnosed by different methods such as modified normalized dc current, current deviation, wavelet, fuzzy, and neural network-based methods, di/dt feedback control, and vector composition of output voltage methods [28].

In this paper, it is assumed that the faulty leg, which is phase "a," was detected and isolated and the phase "a" is connected to the midpoint of the dc capacitors. As a result, the structure of the proposed TPFSC for the SPMSG is shown in Fig. 3.

\section{A. Current Slopes}

The dynamic equations for an SPMSG in rotor rotating reference frame can be presented as follows [20]:

$$
\begin{aligned}
& u_{s d}=R_{s} i_{s d}+\frac{d}{d t} \lambda_{s d}-\omega_{m} \lambda_{s q} \\
& u_{s q}=R_{s} i_{s q}+\frac{d}{d t} \lambda_{s q}+\omega_{m} \lambda_{s d}
\end{aligned}
$$

where $u_{s}, i_{s}, \lambda_{s}, \omega_{m}$, and $R_{s}$ are the stator voltage, the stator current, the stator flux, the electrical rotor speed, and the stator resistance, respectively. The SPMSG stator flux in the rotor reference frame can be expressed as follows:

$$
\begin{aligned}
& \lambda_{s d}=L_{s} i_{s d}+\lambda_{f} \\
& \lambda_{s q}=L_{s} i_{s q}
\end{aligned}
$$

where $\lambda_{f}$ and $L_{s}$ represent the permanent magnets flux and the stator inductance, respectively. The current slopes in the $d q$

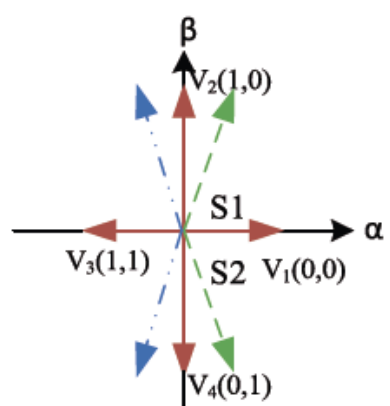

Fig. 4. Voltage vectors positions in the stationary reference frame for a TPFSC Red vectors: $v_{c 1}=v_{c 2}$; green vectors: $v_{c 1}<\mathrm{v}_{c 2}$; blue vectors: $v_{c 1}>v_{c 2}$.

frame can be obtained according to (1)-(4) as follows:

$$
\begin{aligned}
& \frac{d}{d t} i_{s d}=\frac{1}{L_{s}}\left(-R_{s} i_{s d}+\omega_{m} L_{s} i_{s q}+u_{s d}\right) \\
& \frac{d}{d t} i_{s q}=\frac{1}{L_{s}}\left(-R_{s} i_{s q}-\omega_{m} L_{s} i_{s d}-\omega_{m} \lambda_{f}+u_{s q}\right) .
\end{aligned}
$$

As a result, the stator current derivatives can be derived according to the machine parameters, the speed, the permanent magnet flux, the currents, and the applied stator voltage.

\section{B. TPFSC Voltage Vectors}

Four possible combinations of the switch states can be taking place in the TPFSC. When the faulty phase is the phase "a," see Fig. 3, the converter voltage in the $a b c$ frame can be presented as follows:

$$
\left\{\begin{array}{l}
V_{S_{a}}=\frac{1}{3} v_{c 1}\left(-S_{b}-S_{c}\right)+\frac{1}{3} v_{c 2}\left(2-S_{b}-S_{c}\right) \\
V_{S_{b}}=\frac{1}{3} v_{c 1}\left(2 S_{b}-S_{c}\right)+\frac{1}{3} v_{c 2}\left(2 S_{b}-S_{c}-1\right) \\
V_{S_{c}}=\frac{1}{3} v_{c 1}\left(2 S_{c}-S_{b}\right)+\frac{1}{3} v_{c 2}\left(2 S_{c}-S_{b}-1\right)
\end{array}\right.
$$

where $V_{s a}, V_{s b}$, and $V_{s c}$ are the converter voltages in the $a b c$ frame, $v_{c 1}$ and $v_{c 2}$ are the upper and lower capacitor voltages and $S_{b}$ and $S_{c}$ are the switching states of the phase b and c, respectively, which can be 1 or 0 . The converter voltage in the $a b c$ frame can be transferred to the stationary alpha-beta frame according to the Clarke transformation which can be presented as follows:

$$
\left[\begin{array}{l}
v_{S \alpha} \\
v_{S \beta}
\end{array}\right]=\left[\begin{array}{ccc}
1 & -\frac{1}{2} & -\frac{1}{2} \\
0 & \frac{\sqrt{3}}{2} & -\frac{\sqrt{3}}{2}
\end{array}\right]\left[\begin{array}{l}
v_{S a} \\
v_{S b} \\
v_{S c}
\end{array}\right] .
$$

As a result, the converter voltage vectors in the alpha-beta frame can be obtained from (7) and (8). The four possible voltage vectors when the faulty phase is "a," are shown in Fig. 4, and the corresponding values for these four vectors in the stationary and $a b c$ frames are shown in Table I. As can be seen in Table I, the voltage values of $V_{2}$ and $V_{4}$ in the $\alpha$-axis depend on the differences between the upper and lower capacitor voltages. Hence, these two vector phases could change as shown in Fig. 4. For example, when the upper capacitor has a bigger voltage than the lower capacitor, $V_{2}$ and $V_{4}$ will be positioned like the blue lines shown in Fig. 4. 
TABLE I

Four Voltage Vector Values for the TPFSC in the " $\alpha-\beta$ " Stationary and " $a b c$ " Frame

\begin{tabular}{ccc|ccc|cc}
\hline $\mathrm{S}_{\mathrm{b}}$ & $\mathrm{S}_{\mathrm{c}}$ & Vector & $\mathrm{V}_{\mathrm{Sa}}$ & $\mathrm{V}_{\mathrm{Sb}}$ & $\mathrm{V}_{\mathrm{Se}}$ & $\mathrm{V}_{\mathrm{Sa}}$ & $\mathrm{V}_{\mathrm{SB}}$ \\
\hline 0 & 0 & $\mathrm{~V}_{1}$ & $2 v_{c 2} / 3$ & $-v_{c 2} / 3$ & $-v_{c 2} / 3$ & $2 v_{c 2} / 3$ & 0 \\
1 & 0 & $\mathrm{~V}_{2}$ & $\left(v_{c 2}-v_{c 1}\right) / 3$ & $\left(2 v_{c 1}+v_{c 2}\right) / 3$ & $-\left(v_{c 1}+2 v_{c 2}\right) / 3$ & $\left(v_{c 2}-v_{c 1}\right) / 3$ & $\sqrt{3}\left(v_{c 1}+v_{c 2}\right) / 3$ \\
1 & 1 & $\mathrm{~V}_{3}$ & $-2 v_{c 1} / 3$ & $v_{c 1} / 3$ & $v_{c 1} / 3$ & $-2 v_{c 1} / 3$ & 0 \\
0 & 1 & $\mathrm{~V}_{4}$ & $\left(v_{c 2}-v_{c 1}\right) / 3$ & $-\left(v_{c 1}+2 v_{c 2}\right) / 3$ & $\left(2 v_{c 1}+v_{c 2}\right) / 3$ & $\left(v_{c 2}-v_{c 1}\right) / 3$ & $-\sqrt{3}\left(v_{c 1}+v_{c 2}\right) / 3$ \\
\hline
\end{tabular}

TABLE II

Voltage Vector Sequences According to the Stator Voltage Sector

\begin{tabular}{l|lll}
\hline Vector sequence for sector 1: & $\mathrm{V}_{1}$ & $\mathrm{~V}_{2}$ & $\mathrm{~V}_{3}$ \\
\hline Vector sequence for sector 2: & $\mathrm{V}_{1}$ & $\mathrm{~V}_{4}$ & $\mathrm{~V}_{3}$ \\
\hline
\end{tabular}

The stator current slopes for these four voltage vectors can be calculated according to the corresponding voltage values using (5) and (6).

\section{Voltage Vector Sequences and Sector Division Definition}

Three vectors among the four possible voltage vectors are employed in every switching period according to the stator voltage sector, to have fixed switching frequency and low current ripple. In this strategy, two stator voltage sectors are defined, as can be seen in Fig. 4. If the equivalent stator voltage value in the $\beta$-axis is positive, the stator sector is one $\left(S_{1}\right)$, otherwise, the sector is two $\left(S_{2}\right)$. The proposed voltage vector sequences according to the corresponding sector are shown in Table II. As can be seen, in each switching period, $V_{1}$ and $V_{3}$ will be applied. A part of $V_{1}$ or $V_{3}$ and the whole opposite vector will produce the equivalent zero vector.

The switching pattern of the proposed voltage vector sequences when the equivalent stator voltage is in sector $2\left(S_{2}\right)$ is shown in Fig. 5. Three voltage vectors are symmetrically employed in each period. As a result, the stator current at the end of period $(k+1)$ can be presented as follows:

$$
\begin{aligned}
& i_{s q}(k+1)=i_{s q}(k)+S_{q a} t_{a}+S_{q b} t_{b}+S_{q c} t_{c} \\
& i_{s d}(k+1)=i_{s d}(k)+S_{d a} t_{a}+S_{d b} t_{b}+S_{\mathrm{dc}} t_{c}
\end{aligned}
$$

where $S_{q a}, S_{q b}, S_{q c}$ and $S_{d a}, S_{d b}, S_{\mathrm{dc}}$ are the current derivatives of the corresponding voltage vectors in the $q$ - and $d$-axis,

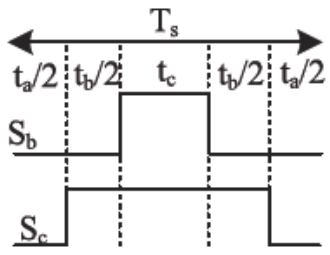

Fig. 5. Proposed MPCC switching pattern for the TPFSC when the stator voltage is in $S_{2}$.

respectively. The duration times of the first, the second, and the third vector are called $t_{a}, t_{b}$, and $t_{c}$, respectively.

The error between the measured current and its reference value at the end of a switching period can be minimized by the following cost function:

$$
G(k+1)=\left(i_{s q}(k+1)-i_{s q}^{*}(k)\right)^{2}+\left(i_{s d}(k+1)-i_{s d}^{*}(k)\right)^{2}
$$

where the superscript $*$ represents the reference values. Substituting (9) and (10) into (11) and considering that the sum of the duration times of the voltage vectors are equal to the switching period time, leads to

$$
\begin{aligned}
G( & +1) \\
= & \left(i_{s q}(k)+S_{q a} t_{a}+S_{q b} t_{b}+S_{q c}\left(T_{s}-t_{a}-t_{b}\right)-i_{s q}^{*}(k)\right)^{2} \\
& +\left(i_{s d}(k)+S_{d a} t_{a}+S_{d b} t_{b}+S_{\mathrm{dc}}\left(T_{s}-t_{a}-t_{b}\right)-i_{s d}^{*}(k)\right)^{2}
\end{aligned}
$$

The optimized duration times which minimize the cost function can be achieved by setting to zero the partial derivatives of (12) with respect to $t_{a}$ and $t_{b}$. Consequently, the optimized duration time of these three vectors can be obtained as follows: eq. 13 and 14 shown at the bottom of this page,

$$
t_{c}=T_{\mathrm{sw}}-t_{a}-t_{b}
$$

where $T_{\mathrm{sw}}$ is the switching period time.

$$
\begin{aligned}
& t_{a}=\frac{\left(i_{s q}(k)-i_{s q}^{*}(k)\right) \cdot\left(S_{d b}-S_{\mathrm{dc}}\right)+\left(i_{s d}(k)-i_{s d}^{*}(k)\right) \cdot\left(S_{q c}-S_{q b}\right)}{S_{d a}\left(S_{q b}-S_{q c}\right)+S_{d b}\left(S_{q c}-S_{q a}\right)+S_{\mathrm{dc}}\left(S_{q a}-S_{q b}\right)}+\frac{T_{s \mathrm{w}}\left(S_{d b} \cdot S_{q c}-S_{\mathrm{dc}} \cdot S_{q b}\right)}{S_{d a}\left(S_{q b}-S_{q c}\right)+S_{d b}\left(S_{q c}-S_{q a}\right)+S_{\mathrm{dc}}\left(S_{q a}-S_{q b}\right)} \\
& t_{b}=\frac{\left(i_{s q}(k)-i_{s q}^{*}(k)\right) \cdot\left(S_{\mathrm{dc}}-S_{d a}\right)+\left(i_{s d}(k)-i_{s d}^{*}(k)\right) \cdot\left(S_{q a}-S_{q c}\right)}{S_{d a}\left(S_{q b}-S_{q c}\right)+S_{d b}\left(S_{q c}-S_{q a}\right)+S_{\mathrm{dc}}\left(S_{q a}-S_{q b}\right)}+\frac{T_{\mathrm{sw}}\left(S_{\mathrm{dc}} \cdot S_{q a}-S_{d a} \cdot S_{q c}\right)}{S_{d a}\left(S_{q b}-S_{q c}\right)+S_{d b}\left(S_{q c}-S_{q a}\right)+S_{\mathrm{dc}}\left(S_{q a}-S_{q b}\right)}
\end{aligned}
$$




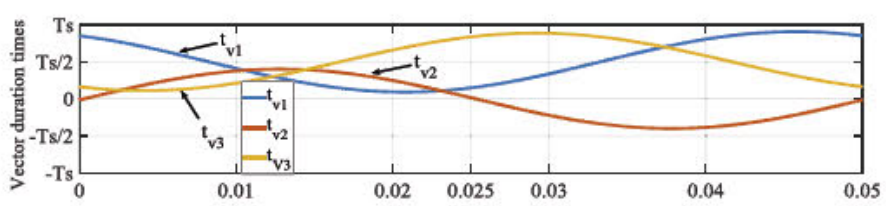

(a)

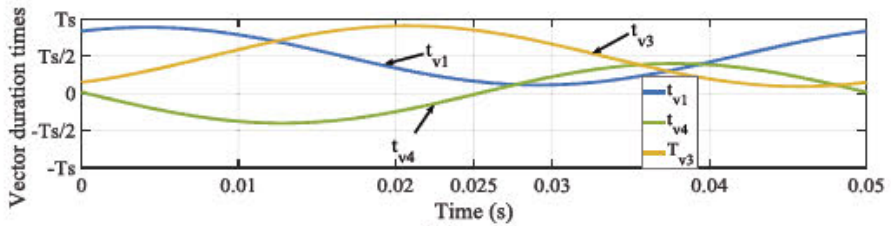

(b)

Fig. 6. Duration times of the voltage vector sequences at steady state for: (a) $V_{1}, V_{2}$ and $V_{3}$; (b) $V_{1}, V_{4}$ and $V_{3}$.

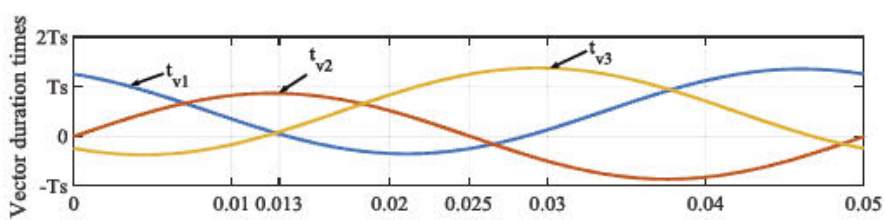

(a)

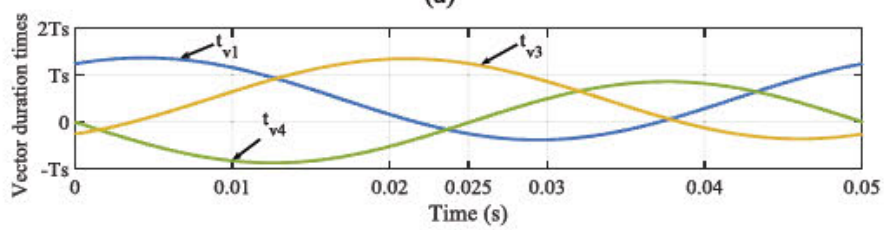

(b)

Fig. 7. Duration times of the voltage vector sequences in a transient state for: (a) $V_{1}, V_{2}$ and $V_{3}$; (b) $V_{1}, V_{4}$ and $V_{3}$.

\section{Identification Algorithm for the Stator Voltage Sector and Correction of the Duration Times}

Fig. 6(a) and (b) show the duration times of the two possible voltage vector sequences during one rotational cycle of the rotor in steady state when the speed is $400 \mathrm{r} / \mathrm{min}$. As can be seen in Fig. 6(a), the duration times of the voltage vector sequence of sector 1, duration times of $\left(V_{1}-V_{2}-V_{3}\right)$, are all positive from the beginning until $t=0.025 \mathrm{~s}$. However, from $t=0.025 \mathrm{~s}$ to the end of the cycle, the duration time for $V_{2}$ has a negative value. In contrast, according to Fig. 6(b), for the other voltage vector sequence $\left(V_{1}-V_{4}-V_{3}\right)$, from the beginning of the cycle to $t=$ $0.025 \mathrm{~s}$, the duration time of $V_{4}$ has a negative value and from $t=0.025 \mathrm{~s}$ to the end of the cycle, the duration times of all vectors of this vector sequence are positive values. This case shows that, from $t=0 \mathrm{~s}$ to $t=0.025 \mathrm{~s}$ and from $t=0.025 \mathrm{~s}$ to $t$ $=0.05 \mathrm{~s}$, the stator voltage reference is located in sector 1 and sector 2, respectively. Consequently, when the duration time of the second vector $\left(t_{b}\right)$ has a negative value in the selected vector sequence, it indicates that the correct vector sequence is the other vector sequence.

Another case can arise during transients or when the required stator voltage is higher than that the converter can generate, since in this situation there is no need to generate a zero-voltage vector by the combination of the two opposite vectors $V_{1}$ and $V_{3}$. Hence, the duration time of $V_{1}$ or $V_{3}\left(t_{a}\right.$ or $\left.t_{c}\right)$ could also become negative as Fig. 7(a) and (b) show.
As a result, the vector that has a negative duration time should be removed from the voltage vector sequence and the other two voltage vectors should be normalized and applied by the MSC. For example, if the required voltage is high, and it is located at the left side of sector 1 , the correct vectors are $V_{2}$ and $V_{3}$ and there is no need to apply $V_{1}$. For instance, as it is shown in Fig. 7(a), from $t=0 \mathrm{~s}$ to $t=0.013 \mathrm{~s}$ the duration times of $V_{1}$ and $V_{2}$ are both positive, whereas the time for $V_{3}$ is negative. This fact shows that the required stator voltage is located at the right side of sector 1 , and there is no need to apply $V_{3}$. Another case is from $t=0.013 \mathrm{~s}$ to $t=0.025 \mathrm{~s}$ when the duration time of $V_{1}$ is negative and the duration times of $V_{2}$ and $V_{3}$ are positive. In this case, there is no need to apply $V_{1}$. As a result, when the estimated duration time of the first or the third voltage vector $\left(t_{a}\right.$ or $t_{c}$ ) has a negative value, the corresponding vector is removed, and the two other vectors should be normalized, which means

$$
\begin{aligned}
& \text { if } t_{c} \leq 0 \Rightarrow\left\{\begin{array}{l}
t^{\prime}{ }_{a}=\frac{t_{a}}{t_{a}+t_{b}} T_{s} \\
t^{\prime}{ }_{b}=\frac{t_{b}}{t_{a}+t_{b}} T_{s} \\
t^{\prime}{ }_{c}=0
\end{array}\right. \\
& \text { if } t_{a} \leq 0 \Rightarrow\left\{\begin{array}{l}
t^{\prime}{ }_{a}=0 \\
t^{\prime}{ }_{b}=\frac{t_{b}}{t_{b}+t_{c}} T_{s} \\
t^{\prime}{ }_{c}=\frac{t_{c}}{t_{b}+t_{c}} T_{s}
\end{array}\right.
\end{aligned}
$$

where $t_{a}^{\prime}, t_{b}^{\prime}$, and $t_{c}^{\prime}$ are the normalized values of the $t_{a}, t_{b}$, and $t_{c}$, respectively. These duration times of the vectors are applied when the duration time of the first or the third vector in the vector sequence gets negative. In this case, the output voltage will be limited to the maximum voltage of the converter without overmodulation.

As aforementioned, when the duration time of second vector $\left(t_{b}\right)$ is negative, the correct vector sequence is the other one. This case also can be seen in Fig. 7(a) and (b). As can be seen in this figure, when the duration time of $V_{2}$ is negative, the duration time of $V_{4}$ is positive and vice versa.

In summary, when the duration time of the second vector $\left(t_{b}\right)$ has a negative value during any situation, transient or steady state, the correct sector is not the one chosen but the other one, and it is necessary to calculate the duration times of the other vector sequence. Moreover, if the duration time of the first or third vector becomes negative, the corresponding vector should be removed, and the duration time of the other two vectors should be normalized according to (16).

\section{E. Voltages Offset Elimination Control}

A voltage offset can appear between the upper and the lower capacitors of the de link due to the ac current flowing through the capacitors. This voltage deviation cause to have unbalanced three phase currents.

According to Fig. 3, the stator current that circulates through the capacitors, in phase "a," can be expressed by the two 
capacitors voltages as follows:

$$
i_{s a}=C \frac{d v_{c 1}}{d t}-C \frac{d v_{c 2}}{d t}
$$

where $C$ is the capacitors value in the dc link and $V_{c 1}$ and $V_{c 2}$ are upper and lower capacitor voltages, respectively. The voltage differences between the upper and the lower capacitors can be derived as follows:

$$
v_{c 1}(t)-v_{c 2}(t)=\frac{1}{C} \int_{0}^{t} i_{s a} d t+v_{c 1}(0)-v_{c 2}(0) .
$$

As a result, the voltage difference is related to the initial value of the capacitors voltage and the faulty phase current. The threephase stator currents will be unbalanced when a voltage offset exists in the capacitors. In this case, the stator currents can be expressed by

$$
\begin{aligned}
& i_{s a}=I_{s} \cos \left(\omega_{m} t\right)-\bar{i}_{s o} \\
& i_{s b}=I_{s} \cos \left(\omega_{m} t-\frac{2 \pi}{3}\right)+\frac{1}{2} \bar{i}_{s o} \\
& i_{s c}=I_{s} \cos \left(\omega_{m} t+\frac{2 \pi}{3}\right)+\frac{1}{2} \bar{i}_{s o}
\end{aligned}
$$

where $i_{s a}, i_{s b}$, and $i_{s c}$ are the three-phase stator currents, $I_{s}$ is the amplitude of the ac current and $\bar{i}_{s o}$ is the dc component current. By transferring the three-phase stator currents to the stationary frame, according to (19)-(21), the current yields to

$$
\begin{aligned}
& i_{s \alpha}=I_{s} \cos \left(\omega_{m} t+\alpha\right)-\bar{i}_{s o} \\
& i_{s \beta}=I_{s} \sin \left(\omega_{m} t+\alpha\right) .
\end{aligned}
$$

As can be seen, the dc component of the current will only be in $\alpha$ axis. According to (18) and (19), the capacitor voltage differences can be represented as follows:

$$
\begin{aligned}
v_{c 1}(t)-v_{c 2}(t)= & \frac{1}{C \omega_{m}} I_{s} \sin \left(\omega_{m} t+\alpha\right)-\frac{\bar{i}_{s o}}{C} t \\
& -\frac{1}{C \omega_{m}} I_{s} \sin (\alpha)+v_{c 1}(0)-v_{c 2}(0) .
\end{aligned}
$$

In (24), only the first term is an ac term in the right side of the equation and the rest of the terms are the dc terms that should have a zero value in order to eliminate the offset. Therefore, the $\bar{i}_{s o}$ needs to be regulated to remove the voltage offset.

If $\frac{i_{s \beta}}{C \omega_{m}}$ is subtracted from both sides in (24), and (23) is substituted in the right side of (24), the result yields to

$$
\begin{aligned}
v_{c 1}(t)-v_{c 2}(t)-\frac{i_{s \beta}}{C \omega_{m}}= & -\frac{1}{C \omega_{m}} I_{s} \sin (\alpha)-\frac{\bar{i}_{s o}}{C} t \\
& +v_{c 1}(0)-v_{c 2}(0) .
\end{aligned}
$$

This equation indicates that by subtracting $\frac{i_{s \beta}}{C \omega_{m}}$ from the capacitor voltage difference, the dc voltage offset can be obtained. Therefore, if the right-hand side of (25) is kept equal to zero, the dc voltage offset will be eliminated. As can be seen in (25), this goal can be achieved by only controlling the $\bar{i}_{s o}$ current. According to (22) and (23), this de current only exists in the $\alpha$-axis

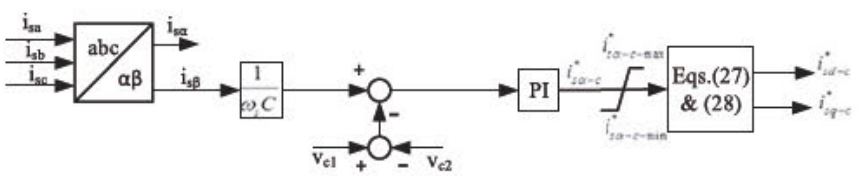

Fig. 8. Block diagram of the proposed voltage deviation control.

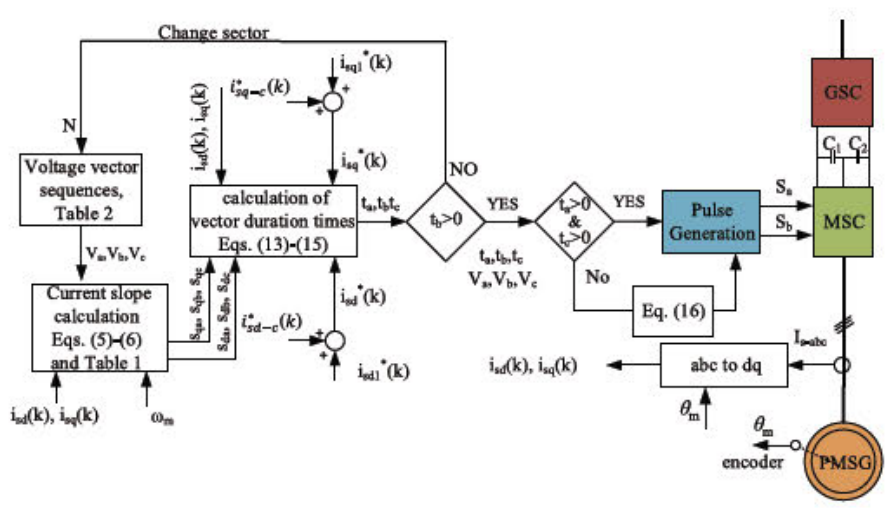

Fig. 9. Block diagram of the proposed MPCC for TPFSC fed PMSG.

component of the stator current. Consequently, by regulating the left-hand side of (25) with a PI controller, the compensation current for removing the voltage offset in the $\alpha$-axis can be presented as follows:

$$
\begin{aligned}
i_{s \alpha-c}^{*}= & -k_{p}\left(v_{c 1}(t)-v_{c 2}(t)-\frac{i_{s \beta}}{C \omega_{m}}\right) \\
& -k_{I} \int\left(v_{c 1}(t)-v_{c 2}(t)-\frac{i_{s \beta}}{C \omega_{m}}\right) d t .
\end{aligned}
$$

This compensation current can be transferred to the synchronous frame as follows:

$$
\begin{aligned}
& i_{s d-c}^{*}=i_{s \alpha-c}^{*} \cos \left(\theta_{m}\right) \\
& i_{s q-c}^{*}=-i_{s \alpha-c}^{*} \sin \left(\theta_{m}\right) .
\end{aligned}
$$

Therefore, the compensation current reference in the $d q$ frame for eliminating the offset voltage can be obtained from (27) and (28). The block diagram of the proposed voltage offset elimination control is presented in Fig. 8.

When the voltage offset elimination control is working, the upper and lower capacitor voltages can be expressed by

$$
v_{c 1}(t)=-v_{c 2}(t)=\frac{1}{2} \frac{1}{C \omega_{m}} I_{s} \sin \left(\omega_{m} t+\alpha\right)+\frac{V_{\mathrm{dc}}}{2} .
$$

The ac term in the capacitor voltage is dependent on the machine speed, the stator current, and the capacitance of the capacitor. So, some type of over voltage protection must be provided as a preventive measure, mainly at low speeds.

\section{F. Overall Proposed Model Predictive Direct Current Control With Voltage Suppression Control for TPFSC Fed SPMSG}

The block diagram of the proposed MPCC with voltage suppression control for the TPFSC fed PMSG is shown in Fig. 9. As can be seen, the current references in the synchronous frame consist of two terms, one is the compensatory term to suppress 
the voltage offset in the capacitors, which is obtained according to Fig. 8, and the other term is the reference value which should be chosen in a way that the maximum power could be obtained from the OWC.

In each period of this control strategy, three voltage vectors are selected according to Table II. It is assumed that the vector sequence is the same as those in the previous period. The current slopes in the synchronous frame are calculated according to (5) and (6) using the rotor speed and the stator current for these three voltage vectors. The duration times of this vector sequence are obtained according to the estimated current slopes and the current references in the $d q$ frame, according to (13)-(15). If these estimated times are positive, this vector sequence and their corresponding times will be applied by the converter. But, if the second vector duration time obtains a negative value, the vector sequence should be changed to the other vector sequence, and the corresponding new durations should be calculated, which led to have a positive duration for the second voltage vector in this new sequence. After this step, as it is shown in Fig. 9, the first and third vector times will be analyzed to check if they are positive or negative. If one of these vectors is negative, the duration times of these vectors are modified according to (16). Finally, these vectors and their durations are applied to the PMSG by the MSC.

\section{OWC-BASED Power Plant EMUlator}

The performance of the proposed MPCC for TPFSC has been tested in a demanding wave energy application. In order to reproduce a wave energy power plant in the laboratory, it was necessary to build an experimental emulator reproducing the components and the behavior of an OWC-based power plant [14], [29]. The control strategy chosen in this paper is to keep the power plant working at the maximum efficiency point by controlling the rotor speed. This section describes how the OWC is modeled in this paper.

\section{A. OWC Emulation}

The OWC is reproduced using the following mathematical models.

1) Irregular Wave Model: Real waves, also called irregular waves, can be reproduced using a variety of mathematical models that represent the state of the free surface of the sea by its energy spectrum, $S(\omega)$. The most known spectra are PiersonMoskowitz [30]-[33], JONSWAP [34]-[37], TMA [30], [38], and Bretschneider [39]. All of them reproduce the sea state keeping the same spectral characteristics (significant height, peak period, etc.) as the original real waves used to obtain the $S(\omega)$.

The Pierson-Moskowitz spectrum was the one chosen in this paper

$$
S(\omega)=\frac{5}{16} \cdot H_{s}^{2} \cdot \omega_{p}^{4} \cdot \omega^{-5} \exp \left[-\frac{5}{4} \cdot\left(\frac{\omega}{\omega_{p}}\right)^{-4}\right]
$$

where $\omega=2 \pi / \mathrm{T}$ is the angular frequency of the wave, $H_{S}$ is the significant wave height, and $\omega_{p}=2 \pi / T_{p}$ is the angular spectral peak frequency.

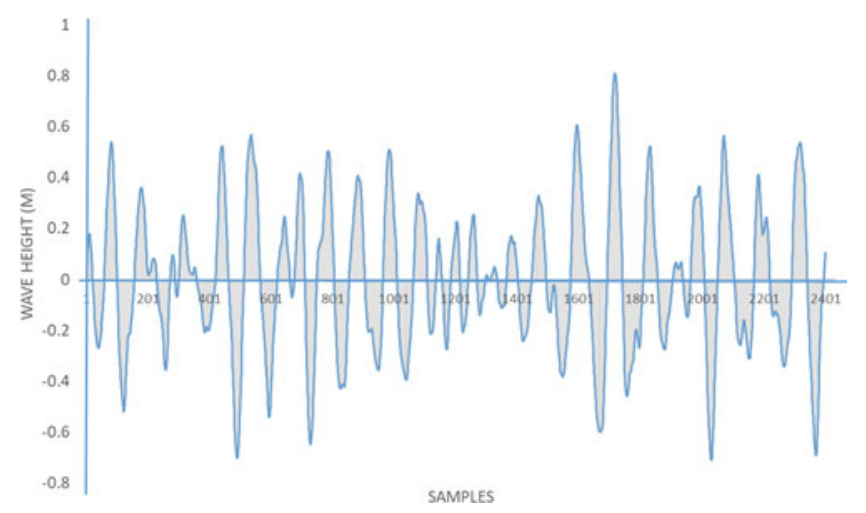

Fig. 10. Real wave profile used in this paper comprises 2400 samples (each sample is 0.1 seconds).

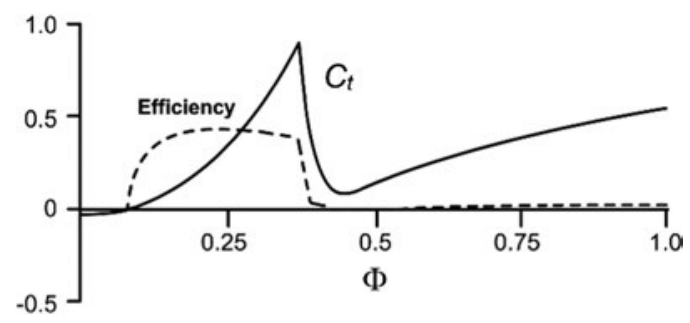

Fig. 11. Ct and efficiency as a function of the flow coefficient.

An irregular wave is represented by the addition of $n$ regular waves, according to the equation

$$
\eta(x, t)=\sum_{i=1}^{n} \zeta_{i} \cdot \cos \left(\omega_{i} t-k_{i} x+\varepsilon_{i}\right)
$$

where $\zeta_{i}$ is the amplitude of each harmonic, which value is calculated from the Pierson-Moskowitz energy spectrum

$$
\zeta_{i}=\sqrt{2 \cdot S\left(\omega_{i}\right) \cdot \Delta \omega_{i}}
$$

Each regular wave is obtained with a random phase with the same probability of occurrence, expressed by a constant probability density in the interval $(-\pi, \pi)$. Fig. 10 shows the real wave profile $\left(H_{s}=1\right.$ and $T_{s}=10$, where $T_{S}$ is the significant wave period) used in the tests carried out in this paper.

2) Chamber Model: The chamber model of an OWC involves a number of complex equations [40]-[42]. However, the model implemented in the emulator uses a set of simplified equations and, as a consequence, the hydrodynamics inside the chamber are not fully described. Nevertheless, from the electrical point of view, the electrical power injected into the grid does not lose the multifrequency spectrum of the wave resource.

The air flow through the chamber presents a speed that is calculated (see Tables IV and V in the Appendix for the nomenclature)

$$
V_{x}=\left(\frac{A_{c}}{A_{d}}\right) \cdot \frac{\partial h_{c}}{\partial t}
$$




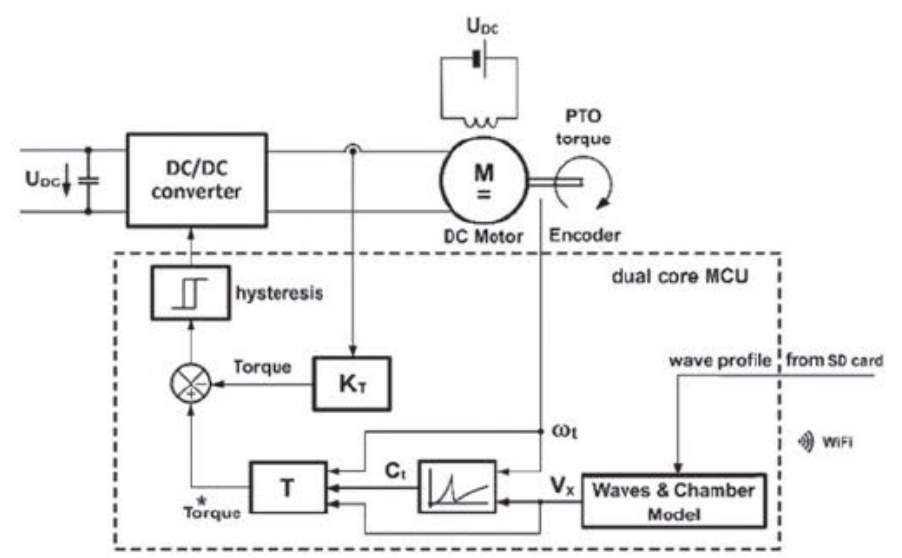

Fig. 12. Control block of the OWC and Wells turbine emulator.

\section{B. Wells Turbine Torque}

The torque developed by the Wells turbine depends on the flow coefficient through the turbine, $\Phi$, Fig. 11 in solid line

$$
\Phi=\frac{V_{x}}{r_{t} \cdot \omega_{t}} .
$$

For a given wave, a dual-core microcontroller, MCU-1 calculates the torque coefficient, $C_{t}$ and obtains the Wells turbine torque

$$
T_{t}=C_{t} \cdot K \cdot \text { Radius } \cdot\left[V_{x}^{2}+\left(\operatorname{Radius} \cdot \omega_{t}\right)^{2}\right] .
$$

This torque value is reproduced in the test bench using the current controlled separately excited dc motor showed in Fig. 12.

\section{PTO Control}

The system described in Section III-A and B generates the same torque as a Wells turbine would apply to the generator shaft, but the corresponding rotary speed depends on the load torque that faces. In this part, another dual-core microcontroller, MCU-2, controls the SPMSG to generate the opposite torque that makes the emulated Wells turbine to work at the maximum efficiency point in every moment. The efficiency curve of the turbine, see Fig. 11, dashed line, provides the value of the $\Phi$ for the maximum efficiency. From this value and calculating $V_{x}$ in every control cycle, MCU- 2 obtains the rotary speed, $\omega_{t}$, for the maximum efficiency and uses it as the reference speed in the SPMSG control system.

\section{Simulation Results}

The simulation studies for a TPFSC feeding an $8.7 \mathrm{~kW}$ SPMSG is carried out in MATLAB/Simulink environment to validate the proposed MPCC. The machine parameters and capacitor values for the simulation studies as well as the experimental tests are illustrated in Table III. The switching frequency and the sampling period are $4 \mathrm{kHz}$ and $250 \mu$ s, respectively. The grid side converter was controlled to maintain the dc-link voltage at $550 \mathrm{~V}$.
TABLE III

SPMSG PARAMETERS

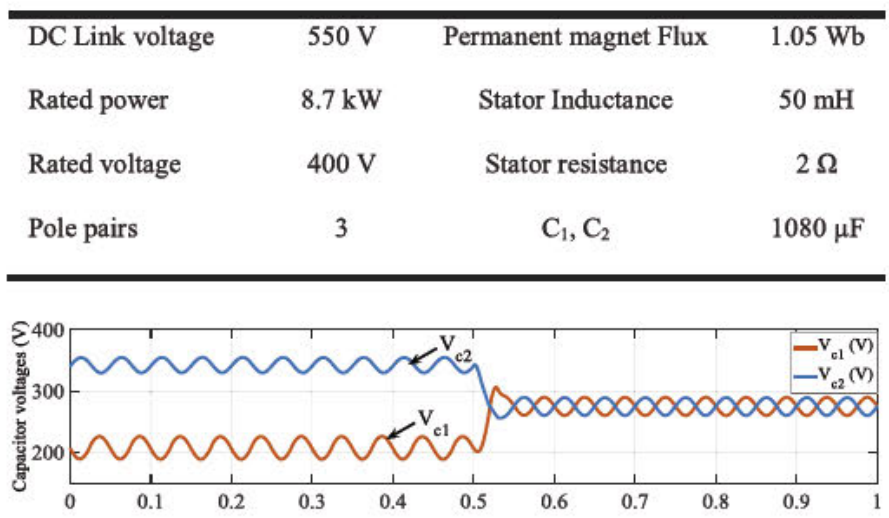

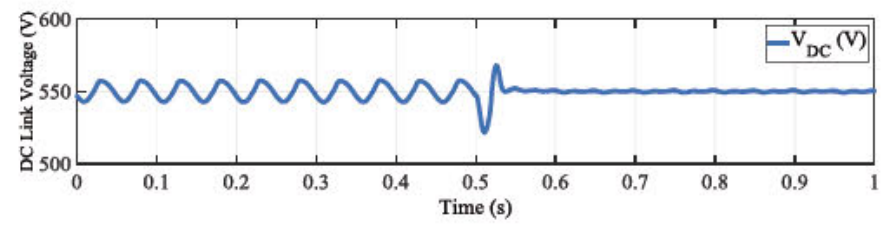

Fig. 13. Simulation results of capacitor voltages and dc-link voltage with and without the offset control.

First, the voltage offset control is tested and the results are shown in Fig. 13. In this study, the $i_{s d}$ and $i_{s q}$ references were set to 0 and $-4 \mathrm{~A}$, respectively. The rotor speed was fixed at $400 \mathrm{r} / \mathrm{min}$ for this case. At the beginning, the voltage offset control was disabled. However, at $t=0.5 \mathrm{~s}$, the compensation currents for removing the offsets were employed. As it can be seen in Fig. 13, the offset voltage between the two capacitors before $t=0.5 \mathrm{~s}$ is about $140 \mathrm{~V}$. Additionally, the total dc-link voltage has oscillations around the $550 \mathrm{~V}$ value when the $\mathrm{dc}$ voltage deviation control is disabled. However, when the offset control is enabled, both capacitors mean voltages are set to $275 \mathrm{~V}$ and the total dc-link voltage oscillation is removed.

The stator currents in the $d q$ and $a b c$ frame, the sector and duration times of the vectors without and with the compensation control are shown in Figs. 14 and 15, respectively. Clearly, the currents in the $d q$ frame could not follow the reference values in some points when the offset control is not working, which led to have a distorted and unbalanced current in phase a. This issue takes place since the upper capacitor $\left(v_{C 1}\right)$ has a lower voltage when there is not an offset control, meaning that the voltage vector $V_{3}$ has a lower value compared to normal situation. Therefore, when the reference voltage is at the end of sector 1 and at the beginning of sector 2, even by employing $V_{3}$ for the whole switching period, the required voltage will not be produced. Consequently, at the end of sector 1 and at the beginning of sector 2 , the currents cannot follow the references when the offset control is not working. On the contrary, the currents are following the reference values when the proposed compensation control is working and, as a result, the currents are sinusoidal and balanced.

To verify the dynamic response, the generator speed was decreased linearly from 500 to $200 \mathrm{r} / \mathrm{min}$ during $1.5 \mathrm{~s}$, as shown in Fig. 16. Furthermore, the $i_{s q}$ and $i_{s d}$ references were changed 

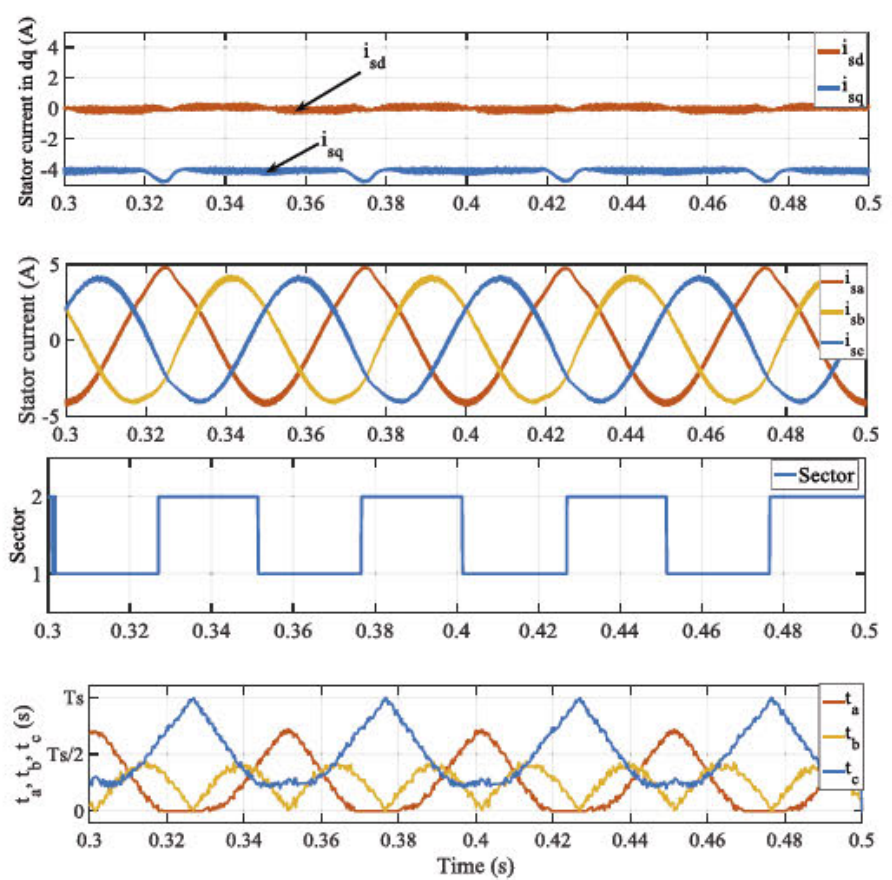

Fig. 14. Simulation results without capacitor voltage offset elimination control.
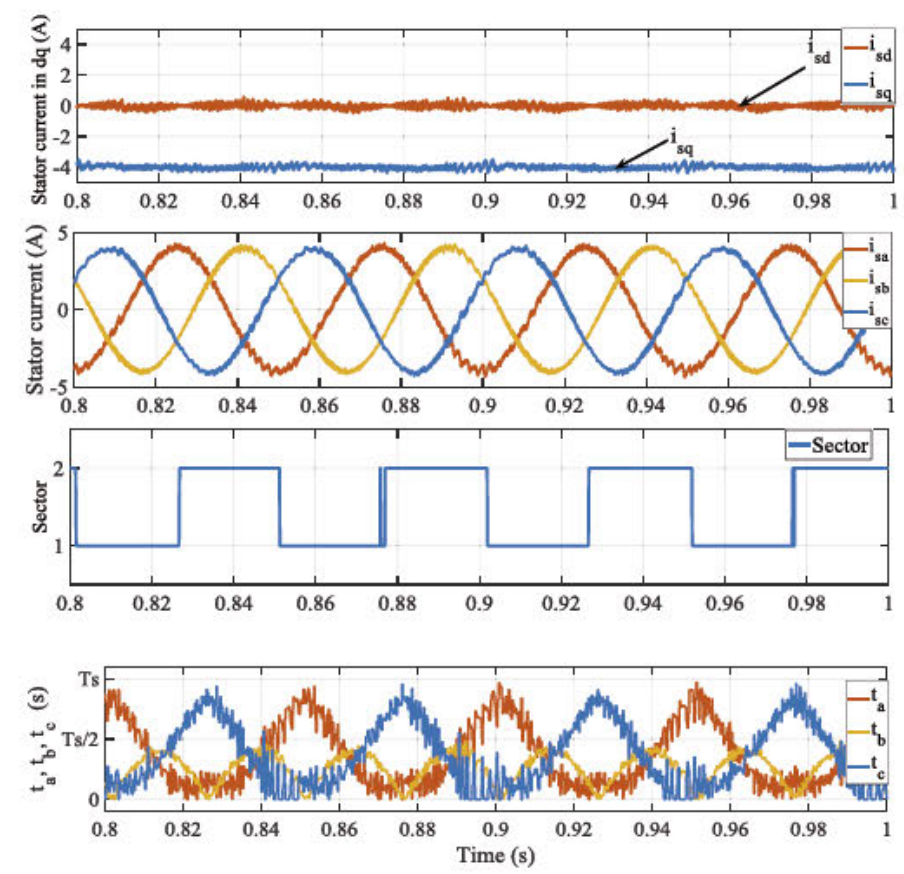

Fig. 15. Simulation results with capacitor voltage offset elimination control.

from -6 to $-3 \mathrm{~A}$ at $t=0.7 \mathrm{~s}$ and from -1 to $1 \mathrm{~A}$ at $t=1 \mathrm{~s}$, respectively. The results are depicted in Fig. 16. In this test, the compensation control was applied for the whole test. The results indicate that the currents follow the reference values rapidly during different rotor speeds, while the capacitor voltage offset remained at zero for the whole test. Moreover, the three-phase currents are balanced due to the offset control.

The proposed model predictive control for TPFSC is compared with two previous predictive controls, one voltage vector [43] and two voltage vector predictive controls [44], for this
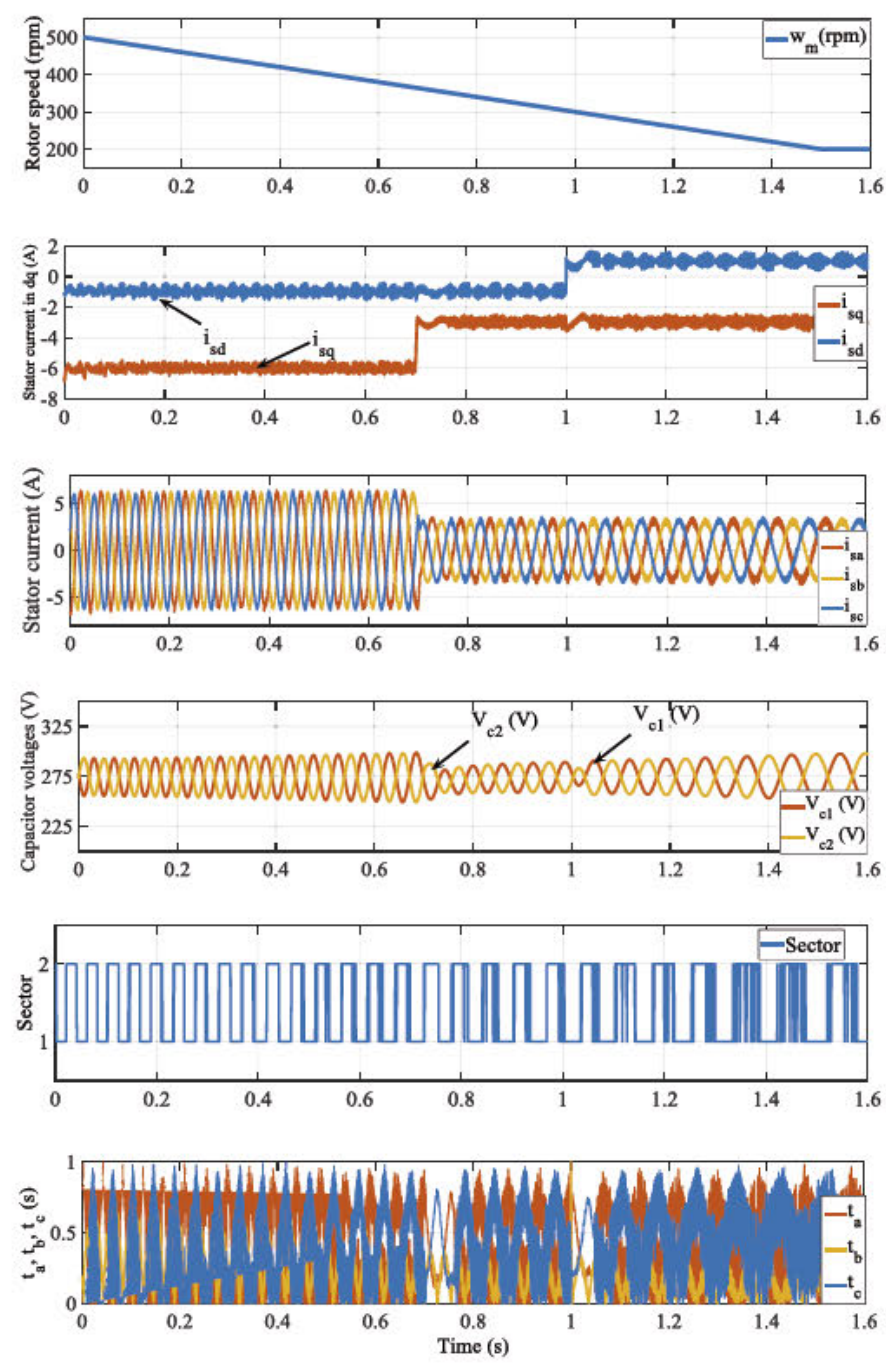

Fig. 16. Simulation results during a rotor speed variation with current step changes.

same converter topology at the same switching frequency. In this test, the rotor speed was $400 \mathrm{r} / \mathrm{min}$ and the current references for $d$ and $q$ are set to 0 and $-6 \mathrm{~A}$, respectively. The three-phase stator currents and current total harmonic distortion (THD) for this comparison are shown in Figs. 17 and 18, respectively. The results show that the stator current for the proposed method is sinusoidal, balanced, and free of ripples when compared to the two previous predictive strategies. The stator current THD for the one voltage vector predictive control, two voltage vector predictive control, and the proposed strategy are $10.22 \%$, $5.96 \%$, and $3.47 \%$, respectively. Moreover, the low-order harmonics are decreased with the proposed control method while for the two previous control methods, these harmonics are notable. It should be noted that the current THD for three-phase six switches converter with the same reference values would be $1.32 \%$ in this case (pre-fault situation).

\section{EXPERIMENTAL RESULTS}

The proposed MPCC of a TPFSC for SPMSG was tested in a wave energy application using the experimental setup shown in Figs. 19 and 20. This setup consists of: Part 1: OWC Power 


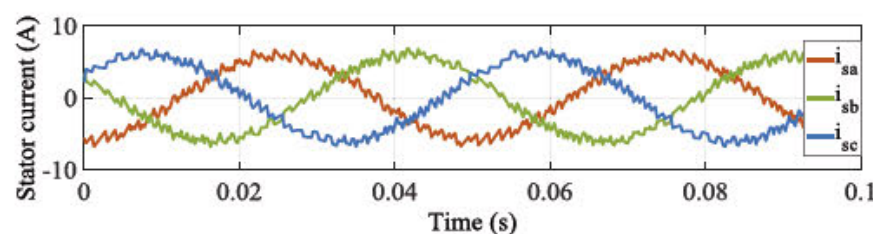

(a)

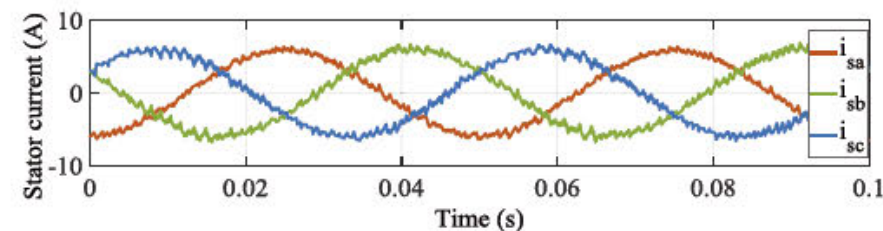

(b)

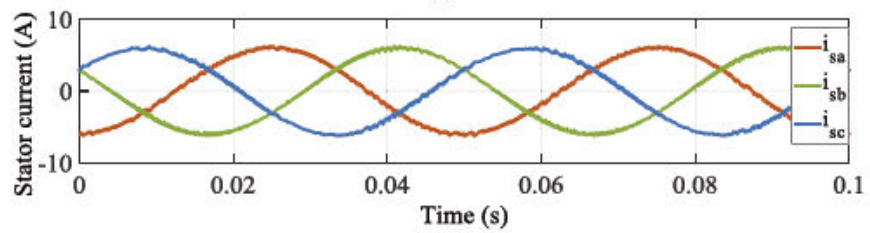

(c)

Fig. 17. Three-phase stator current. (a) One voltage vector predictive control. (b) Two voltage vector predictive control. (c) Proposed model predictive control.

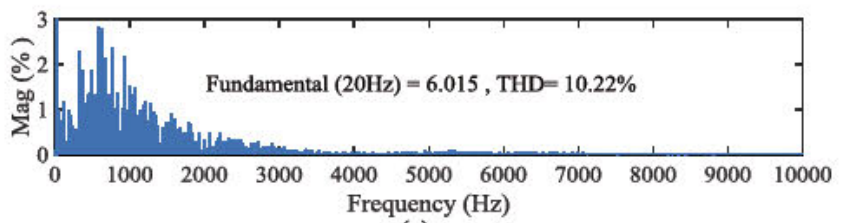

(a)

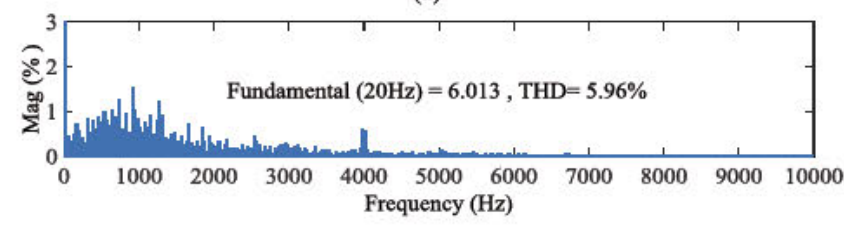

(b)

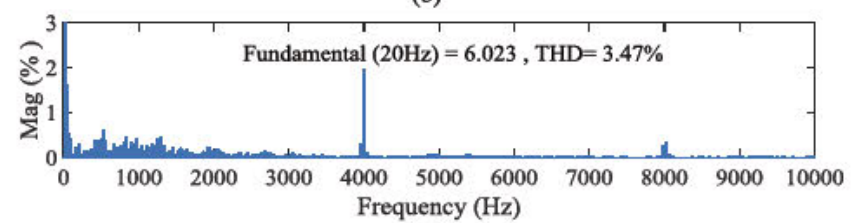

(c)

Fig. 18. Stator current THD. (a) One voltage vector predictive control. (b) Two voltage vector predictive control. (c) Proposed model predictive control.

Plant, which reproduces the waves, OWC models, and actual torque developed by a Wells turbine emulated by means of a dc-dc converter and a de machine; Part 2: Power Take Off, where a TPFSC is connected to the SPMSG and is controlled with the proposed MPCC; and Part 3: Grid connection, which injects into the grid the energy that has been absorbed from the waves. Each of these three parts is controlled using a dual-core F28M35x Concerto MCU of Texas Instruments. The switching frequency and the sampling time for the MSC were selected to be $4 \mathrm{kHz}$ and $250 \mu \mathrm{s}$. All of the waveforms were recorded using the F28M35x itself, except the stator currents, that were recorded using a Tektronix TDS2024C oscilloscope with a sampling time of $100 \mu \mathrm{s}$. The dc-link voltage was set to $550 \mathrm{~V}$ during the

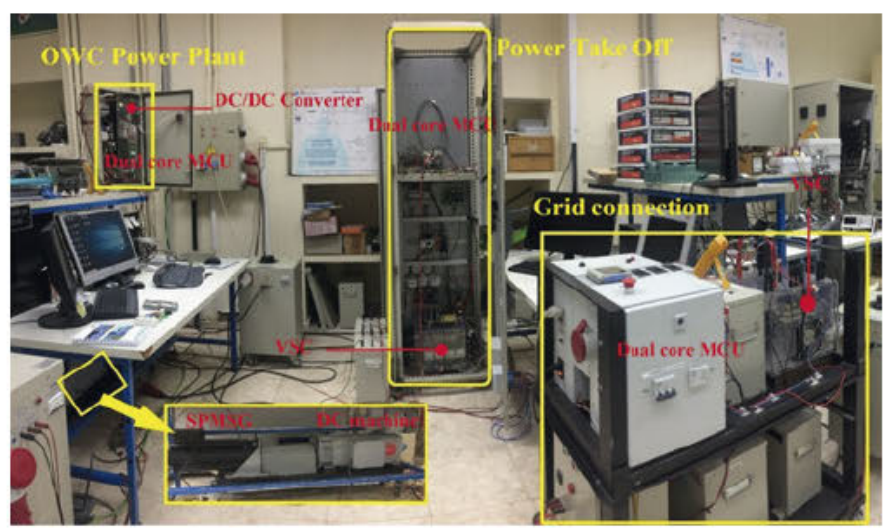

Fig. 19. Photo of the experimental setup used to reproduce an OWC-based power plant.

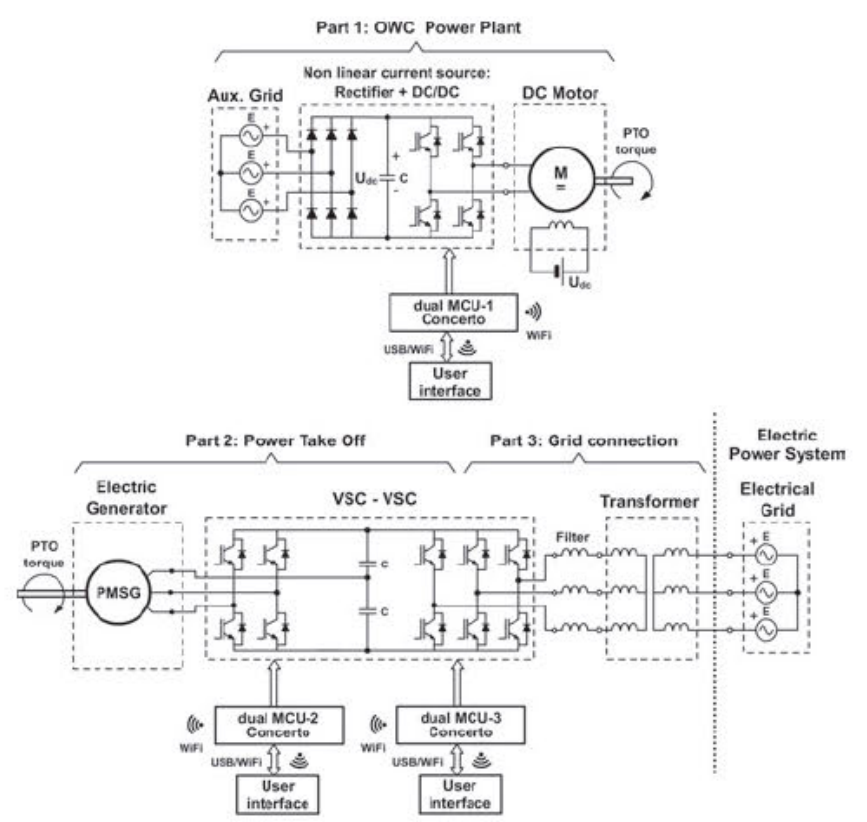

Fig. 20. Electrical scheme of the setup used to carry out the experimental tests.

experimental tests. The machine parameters and the capacitor values are illustrated in Table III. The capacitor values for the TPFSC are the same capacitor values that are used in the threephase six switches converters.

Three types of experimental tests were carried out: first, a steady-state test to check the proper operation of the control system. Second, three transient tests to check the performance of the control system during changes of the $i_{s d}$ and $i_{s q}$ references and when facing a rotor speed step. Finally, a transient test reproducing the behavior of an OWC wave energy power plant. In all of these tests, the voltage offset elimination control was enabled.

\section{A. Steady-State Test}

In this first test, the rotor speed was set to $450 \mathrm{r} / \mathrm{min}$, as can be seen in Fig. 21, by means of the dc motor, whereas the values for the $i_{s d}$ and $i_{s q}$ references were set to 0 and $-4 \mathrm{~A}$, respectively. Fig. 22 shows the currents in the $d-q$ frame. As 


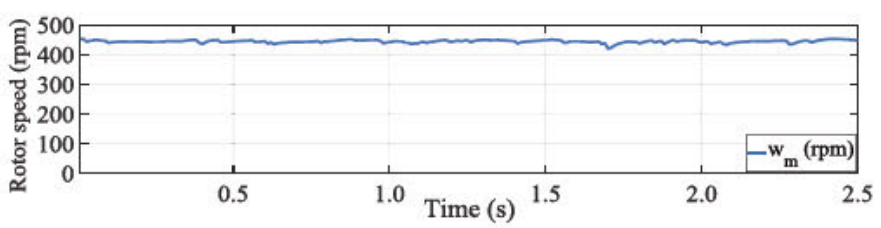

Fig. 21. Rotor speed during the steady-state test.

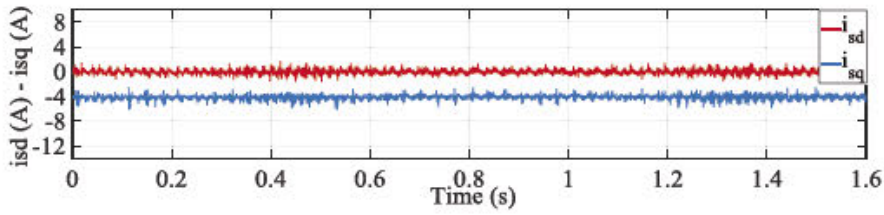

Fig. 22. Values of $i_{s d}$ (red) and $i_{s q}$ (blue) obtained from the phase current measurements.

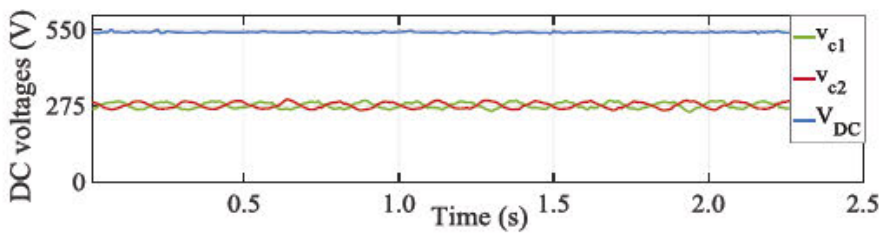

Fig. 23. DC voltages in $\mathrm{C} 1$ (light green) and $\mathrm{C} 2$ (red) and DC-link voltage (blue) during the steady-state test.

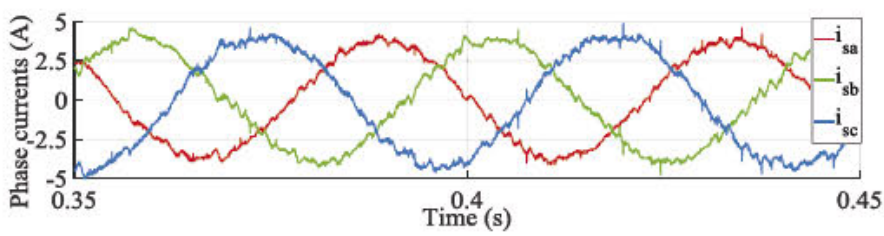

Fig. 24. Three phase stator current of the SPMSG during the steady-state test.

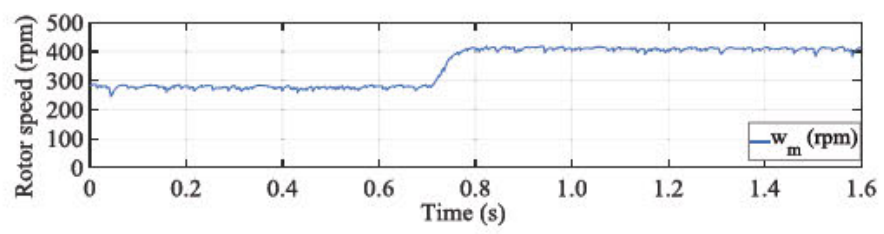

Fig. 25. SPMSG rotor speed during the speed transient test.

can be checked, the currents are following the reference values perfectly. The dc-link voltage and the capacitor voltages are shown in Fig. 23. As can be noticed in this figure, the dc-link voltage is smooth without practically any ripple. Moreover, the capacitor voltages are balanced, and the voltage mean value for each of the capacitors is $275 \mathrm{~V}$, which shows the effectiveness of the proposed voltage offset elimination control. Fig. 24 shows the three-phase current proving that the proposed control system was able to obtain sinusoidal currents, despite the lack of two IGBTs with respect to the standard two-level converter topology.

\section{B. Speed Transient Test}

This test was meant to check the capability of the proposed control to maintain the $i_{s d}$ and $i_{s q}$ currents, and consequently, the torque and magnetic field of the SPMSG, close to their references when the rotary speed faces a step change from 270 to $400 \mathrm{r} / \mathrm{min}$, as shown in Fig. 25. The test was carried out by

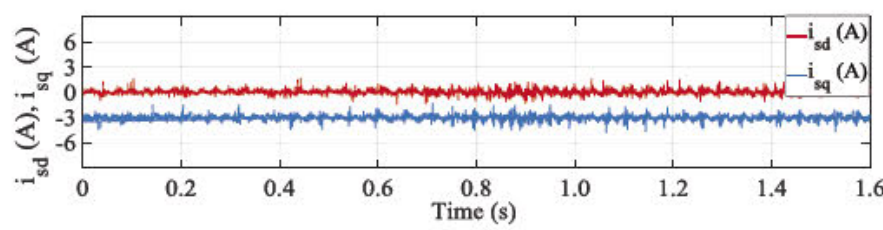

Fig. 26. $i_{s d}$ (red) and $i_{s q}$ (blue) currents during the speed transient test.

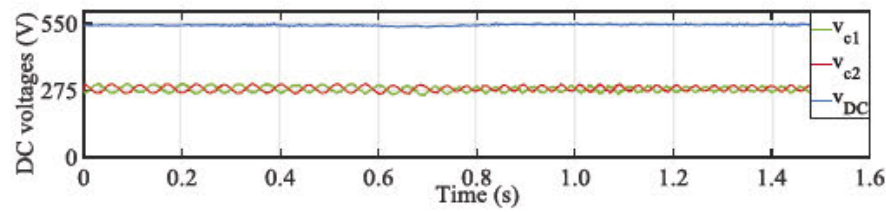

Fig. 27. DC voltages in C1 (light green) and C2 (red) and dc-link voltage (blue) during the speed transient test.

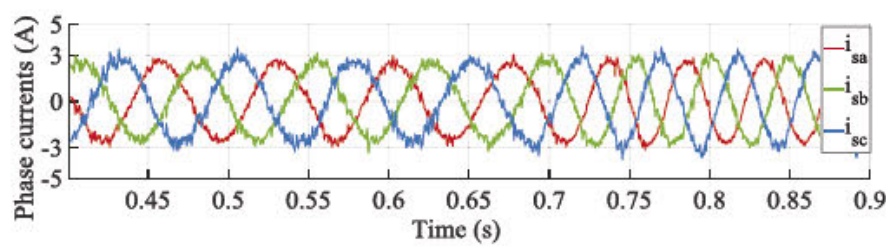

Fig. 28. Phase currents at the stator of the PMSM during the speed transient test.

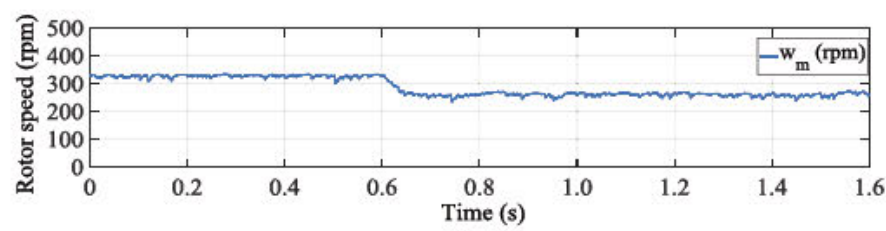

Fig. 29. SPMSG rotor speed during the $i_{s q}$ transient test.

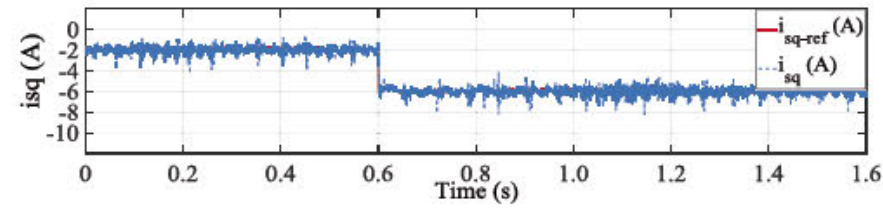

Fig. 30. $i_{s q}$ reference (red) and actual $i_{s q}$ (blue) during the $i_{s q}$ transient test.

applying a dc voltage-step to the armature winding of the $\mathrm{dc}$ motor. Fig. 26 shows that the $i_{s d}$ and $i_{s q}$ remained constant despite the speed step. Fig. 27 shows the capacitor voltages during this test. The two capacitor voltages and the total dc-link voltage remained stable when the rotor speeds up during this test. Finally, Fig. 28 shows the three-phase stator current during the speed step that took place in the SPMSG. It can be checked clearly that the frequency of the stator current is increased after the step.

\section{C. $i_{s q}$ Transient Test}

In this test, the SPMSG torque was increased through the $i_{s q}$ reference from -2 to $-6 \mathrm{~A}$, whereas the dc motor supply remained unchanged. As a result, the rotor speed decreased as the load torque generated by the SPMSG temporarily exceeded the motor torque provided by the dc motor. The rotor speed is shown in Fig. 29. Figs. 30 and 31 show the fast dynamic 


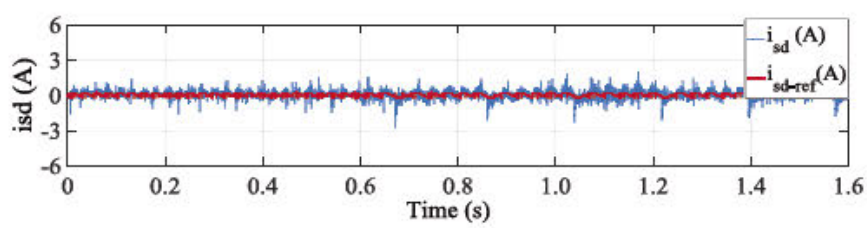

Fig. 31. $i_{s d}$ reference (red) and actual $i_{s d}$ (blue) during the $i_{s q}$ transient test.

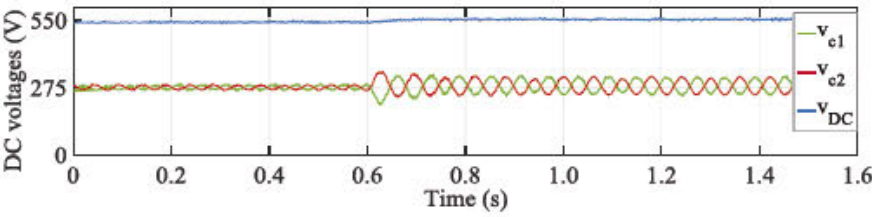

Fig. 32. DC voltages in C1 (light green) and C2 (red) and DC-link voltage (blue) during the $i_{s q}$ transient test.

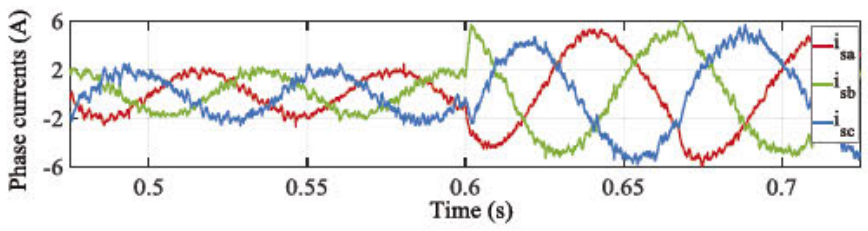

Fig. 33. Phase currents at the stator of the SPMSG around the point where the $i_{s q}$ transient takes place.

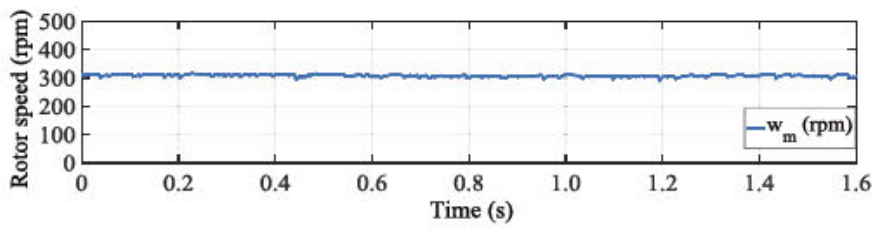

Fig. 34. Rotor speed during the $i_{s d}$ transient test.

response of the proposed control. As can be seen, the $i_{s q}$ follows the step in the reference with great accuracy and $i_{s d}$ remains to zero at every moment. The capacitor voltages are shown in Fig. 32. The dc voltages in $\mathrm{C} 1$ and $\mathrm{C} 2$ experimented a higher fluctuation after the transient due to the higher current demand and the lower speed. As can be checked in this figure, the voltage offset control works perfectly and quickly during the transient test and both capacitors mean voltage value is maintained at 275 V. Finally, Fig. 33 shows the sinusoidal currents near the $i_{s q}$ transient test, where the waveforms get adapted to the new amplitude immediately, keeping a low distortion.

\section{D. $i_{s d}$ Transient Test}

In this test, the SPMSG changes from a field weakening operation point to an overexcited point $\left(i_{s d}=-1 \mathrm{~A}\right.$ to $\left.i_{s d}=+2 \mathrm{~A}\right)$, maintaining the torque constant through $i_{s q}=-4 \mathrm{~A}$. The field weakening was limited to $-1 \mathrm{~A}$ on purpose to avoid the irreversible demagnetization of the magnets.

The results are shown in Figs. 34-38. The rotor speed is fixed at $300 \mathrm{r} / \mathrm{min}$ as can be seen in Fig. 34. The $i_{s d}$ and $i_{s q}$ currents for this test are shown in Figs. 35 and 36, respectively. The results show that the $i_{s d}$ follows the reference value perfectly in the proposed MPCC, while the $i_{s q}$ is kept unchanged. The three-phase stator current is illustrated in Fig. 37 which shows

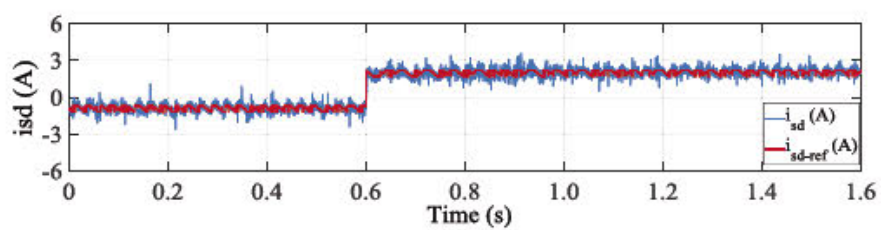

Fig. 35. $i_{s d}$ reference (red) and actual $i_{s d}$ (blue) during the $i_{s d}$ transient test.

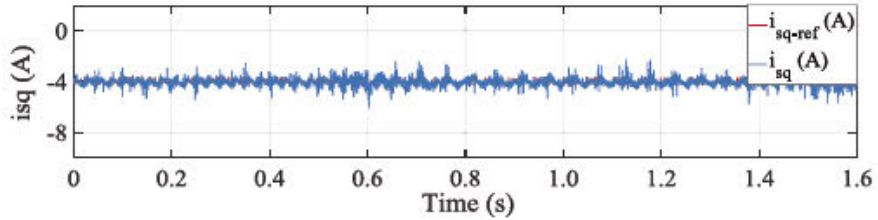

Fig. 36. $i_{s q}$ reference (red) and actual $i_{s q}$ (blue) during the $i_{s d}$ transient test.

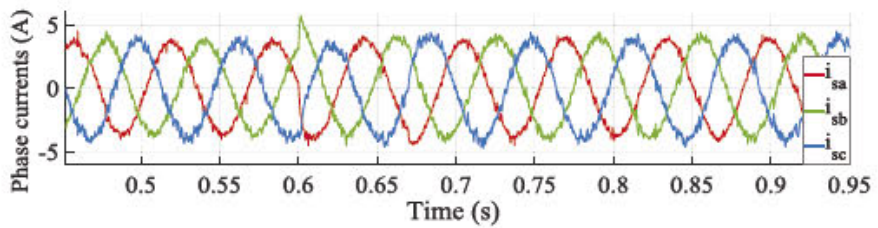

Fig. 37. Phase currents at the stator of the SPMSG around the point where the transient takes place.

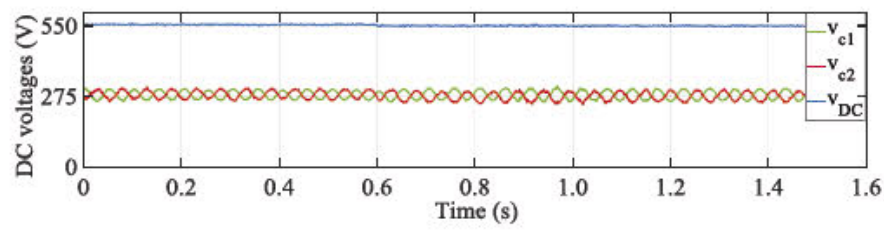

Fig. 38. DC voltages in C1 (light green) and C2 (red) and dc-link voltage (blue) during the $i_{s d}$ transient test.

that the good quality of the sinusoidal current continued after a brief transient. Fig. 38 shows that the voltage offset control is working properly during the transient while keeping the mean value of the capacitor voltages at the set point value.

\section{E. Tests Using the OWC Emulator}

The final test was intended to study the proposed control system to be used in an OWC-based power plant. The lack of two IGBTs could mean a reduction of the control capability of the electronic converter, forcing to disconnect it from the electrical grid, leading to a reduction of profits.

The test was carried out for the wave profile showed in Fig. 10 and lasted $4 \mathrm{~min}$. The six microcontrollers that comprise the emulator take care of calculating the air speed in the duct of the OWC, the Wells turbine torque, the Wells turbine maximum efficiency speed to be imposed by the PTO, etc., throughout the entire test, at every control cycle.

In Fig. 39, the Wells turbine maximum efficiency speed and the actual speed are shown in blue and red lines, respectively, throughout the $240 \mathrm{~s}$ of the test. This figure shows that the rotary speed of the generator follows the reference speed with great accuracy with the proposed MPCC during the $4 \mathrm{~min}$ that lasted the test, in the entire range of speed containing fast and slow 


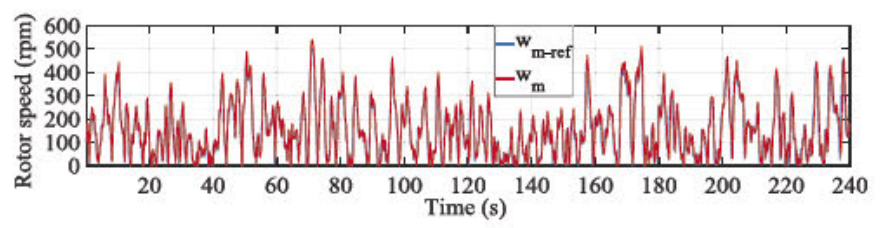

Fig. 39. Speed reference (blue) and actual speed (red) of the SPMSG along the 4 min test.

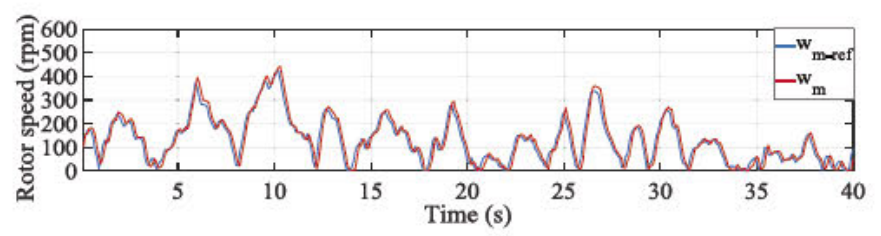

Fig. 40. Detailed view of the speed reference (blue) and actual speed (red) of the SPMSG along the first $40 \mathrm{~s}$ of the test.

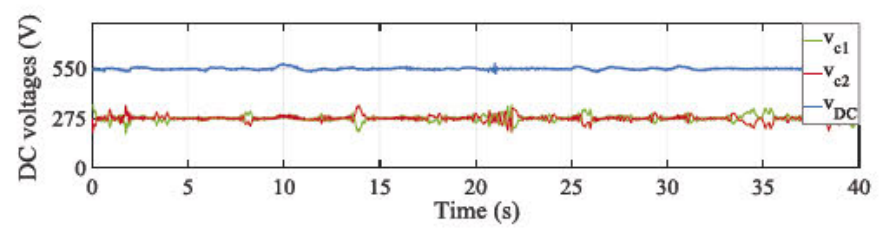

Fig. 41. DC voltages in $\mathrm{C} 1$ (light green) and C2 (red) and dc-link voltage (blue) during the test.

reference speed changes. Fig. 40 provides a more detailed view throughout the first $40 \mathrm{~s}$ of the test.

Another critical issue is to check the performance of the voltage offset elimination control during this test since, if it is not fast and accurate enough, it could lead to the breakdown of the capacitors. Fig. 41 shows the capacitor voltages and the dc-link voltage of the first $40 \mathrm{~s}$ of the test. It can be seen that the proposed method was capable of eliminating the voltage offset of the capacitors during the huge variations of speed, which indicates the effectiveness of the proposed MPCC and the offset elimination control.

\section{CONCLUSION}

This paper presented a simple model predictive current control with capacitor voltage offset elimination control for the TPFSC feeding a SPMSG. The proposed method features a fixed switching frequency and a fast dynamic response despite the fact that it is working with only four switches. In every switching period, three voltage vectors are employed according to the current references and the rotor speed. The proposed capacitor voltage suppression control removes the voltage offset in the capacitors rapidly without needing to obtain the mean values of the capacitor voltages using a low-pass filter which would be difficult at low speeds.

Despite the lack of two IGBTs in the power take off system, the proposed MPCC system has proven to be able to set and keep the references, basically the torque and magnetic field controlled by $i_{s q}$ and $i_{s d}$ as well as to remove the voltage offset of the capacitors, during both steady state and speed transients. Also, when it comes to references' transients, the experimental results showed that this system features a very fast dynamic response and a total independence in the control of $i_{s d}$ and $i_{s q}$. Besides, the proposed voltage offset suppression control works perfectly and rapidly even when the rotor speed is low, and the speed variations are high.

Additionally, the proposed method was compared to other two previous predictive controls for the TPFSC. The results showed that the proposed predictive control has less low-order harmonics in the stator current and low current THD compared to predictive controls based on one voltage vector and two voltage vectors. In this study, the current THD for predictive control was $3.47 \%$, while for the predictive controls based on one voltage vectors, and two voltage vectors were $10.22 \%$ and $5.96 \%$, respectively.

Finally, the highly demanding speed test corresponding to the control of an OWC-based power plant has demonstrated the capability of this control system to follow the maximum efficiency speed reference of the Wells turbine, whereas the capacitor voltage offset was eliminated during the test. As a result, the power plant could keep generating power despite the fault in the power converter. This feature could be also helpful in the case of buoy-based WECs since it allows to keep the control of the buoy in the case of a breakdown in the power converter.

\section{APPENDIX: NOMENCLATURE}

TABLE A1

CHAMBER MODEL

\begin{tabular}{ll}
$V_{x}$ & Air speed in the duct $(\mathrm{m} / \mathrm{s})$ \\
$\mathrm{h}_{\mathrm{c}}$ & Height of the free water surface inside the chamber $(\mathrm{m})$ \\
$\mathrm{A}_{\mathrm{c}}$ & Chamber cross section $\left(\mathrm{m}^{2}\right)$ \\
$\mathrm{A}_{\mathrm{d}}$ & Duct cross section $\left(\mathrm{m}^{2}\right)$ \\
\hline
\end{tabular}

TABLE A2

TURBINE MODEL

\begin{tabular}{cccc}
\hline $\mathrm{T}_{\mathrm{t}}$ & Shaft torque (N.m) & $\mathrm{r}_{\mathrm{t}}$ & Turbine radius (m). \\
$\phi$ & $\begin{array}{c}\text { Flow coefficient (non- } \\
\text { dimensional) }\end{array}$ & $\mathrm{V}_{\mathrm{x}}$ & Air speed in duct $(\mathrm{m} / \mathrm{s})$. \\
$\mathrm{C}_{\mathrm{t}}$ & $\begin{array}{c}\text { Torque coefficient (non- } \\
\text { dimensional) }\end{array}$ & $\omega_{\mathrm{t}}$ & $\begin{array}{c}\text { Angular velocity of rotor system } \\
(\mathrm{rad} / \mathrm{s})\end{array}$ \\
$\mathrm{K}$ & Constant of the turbine $(\mathrm{kg} / \mathrm{m})$ & & \\
\hline
\end{tabular}

\section{REFERENCES}

[1] W. Sheng and A. Lewis, "Power takeoff optimization to maximize wave energy conversions for oscillating water column devices," IEEE J. Oceanic Eng., vol. 43, no. 1, pp. 36-47, Jan. 2018.

[2] A. F. de and O. Falcao, "First generation wave power plants: Current status and R\&D requirements," in Proc. ASME 22nd Int. Conf. Offshore Mech. Arctic Eng., 2003, pp. 723-731.

[3] J. F. Kelly, W. M. D. Wright, W. Sheng, and K. O'Sullivan, "Implementation and verification of a wave-to-wire model of an oscillating water column with impulse turbine," IEEE Trans. Sustain. Energy, vol. 7, no. 2 , pp. 546-553, Apr. 2016.

[4] S. K. Mishra, S. Purwar, and N. Kishor, "Event triggered nonlinear control of OWC ocean wave energy plant," IEEE Trans. Sustain. Energy, vol. 9, no. 4 , pp. 1750-1760, Oct. 2018.

[5] N. Delmonte, D. Barater, F. Giuliani, P. Cova, and G. Buticchi, "Review of oscillating water column converters," IEEE Trans. Ind. Appl., vol. 52 , no. 2, pp. 1698-1710, Mar/Apr. 2016. 
[6] S. S. Yegna Narayanan, B. K. Murthy, and G. Sridhara Rao, "Dynamic analysis of a grid-connected induction generator driven by a wave-energy turbine through hunting networks," IEEE Trans. Energy Convers., vol. 14, no. 1, pp. 115-121, Mar. 1999.

[7] M. Alberdi et al., "Complementary control of oscillating water column based wave energy conversion plants to improve the instantaneous power output," IEEE Trans. Energy Convers., vol. 26, no. 4, pp. 1021-1032, Dec. 2011.

[8] S. Ceballos et al., "Efficiency optimization in low inertia Wells turbine oscillating water column devices," IEEE Trans. Energy Convers., vol. 28, no. 3, pp. 553-564, Sep. 2013.

[9] Y. Torre-Enciso, I. Ortubia, L. I. López de Aguileta, and J. Marqués, "Mutriku wave power plant: From the thinking out to the reality," in Proc. 8th Eur. Wave Tidal Energy Conf., Uppsala, Sweden, 2009, pp. 1-11.

[10] M. Amundarain, M. Alberdi, A. J. Garrido, and I. Garrido, "Modeling and simulation of wave energy generation plants: Output power control," IEEE Trans. Ind. Electron., vol. 58, no. 1, pp. 105-117, Jan. 2011.

[11] A. J. Garrido, I. Garrido, M. Amundarain, M. Alberdi, and M. De la Sen, "Sliding-mode control of wave power generation plants," IEEE Trans. Ind. Appl., vol. 48, no. 6, pp. 2372-2381, Nov./Dec. 2012.

[12] M. S. Lagoun, A. Benalia, and M. E. H. Benbouzid, "A predictive power control of Doubly fed induction generator for wave energy converter in irregular waves," in Proc. 1st Int. Conf. Green Energy, Sfax, Tunisia, 2014, pp. 26-31.

[13] A. O. Di Tommaso, R. Miceli, G. Ricco Galluzzo, and M. Trapanese, "Efficiency maximization of permanent magnet synchronous generators coupled to wind turbines," in Proc. IEEE Power Electron. Spec. Conf., Orlando, FL, USA, Jun. 2007, pp. 1267-1272.

[14] D. Ramirez, J. P. Bartolome, S. Martinez, L. C. Herrero, and M. Blanco, "Emulation of an OWC ocean energy plant with PMSG and irregular wave model," IEEE Trans. Sustain. Energy, vol. 6, no. 4, pp. 1515-1523, Oct. 2015.

[15] N. M. A. Freire and A. J. M. Cardoso, "A fault-tolerant direct controlled PMSG drive for wind energy conversion systems," IEEE Trans. Ind. Electron., vol. 61, no. 2, pp. 821-834, Feb. 2014.

[16] Z. Zeng, W. Zheng, R. Zhao, C. Zhu, and Q. Yuan, "Modeling, modulation, and control of the three-phase four-switch PWM rectifier under balanced voltage," IEEE Trans. Power Electron., vol. 31, no. 7, pp. 4892-4905, Jul. 2016.

[17] D. Zhou, X. Li, and Y. Tang, "Multiple-vector model-predictive power control of three-phase four-switch rectifiers with capacitor voltage balancing," IEEE Trans. Power Electron., vol. 33, no. 7, pp. 5824-5835, Jul. 2018.

[18] T. S. Lee and J. H. Liu, "Modeling and control of a three-phase fourswitch PWM voltage-source rectifier in d-q synchronous frame," IEEE Trans. Power Electron., vol. 26, no. 9, pp. 2476-2489, Sep. 2011.

[19] S. Biricik and H. Komurcugil, "Three-level hysteresis current control strategy for three-phase four-switch shunt active filters," IET Power Electron., vol. 9, no. 8, pp. 1732-1740, Jun. 2016.

[20] H. Fadil, D. Yousfi, M. L. Elhafyani, Y. A. Driss, and A. R. Nasrudin, "Four-switch three-phase PMSM converter with output voltage balance and DC-link voltage offset suppression," in Proc. Int. Conf. Elect. Sci. Technol. Maghreb, Marrakech, Morocco, 2016, pp. 1-7.

[21] C. Zhu, Z. Zeng, and R. Zhao, "Comprehensive analysis and reduction of torque ripples in three-phase four-switch inverter-fed PMSM drives using space vector pulse-width modulation," IEEE Trans. Power Electron., vol. 32, no. 7, pp. 5411-5424, Jul. 2017.

[22] C. Zhu, Z. Zeng, and R. Zhao, "Torque ripple elimination based on inverter voltage drop compensation for a three-phase four-switch inverterfed PMSM drive under low speeds," IET Power Electron., vol. 10, no. 12, pp. 1430-1437, 2017

[23] Z. Zeng, C. Zhu, X. Jin, W. Shi, and R. Zhao, "Hybrid space vector modulation strategy for torque ripple minimization in three-phase fourswitch inverter-fed PMSM drives," IEEE Trans. Ind. Electron., vol. 64, no. 3, pp. 2122-2134, Mar. 2017.

[24] D. Zhou, J. Zhao, and Y. Liu, "Predictive torque control scheme for threephase four-switch inverter-fed induction motor drives with DC-link voltages offset suppression," IEEE Trans. Power Electron., vol. 30, no. 6, pp. 3309-3318, Jun. 2015.
[25] J. Su and D. Sun, "Simplified MPCC for four-switch three-phase inverter-fed PMSM," Electron. Lett., vol. 53, no. 16, pp. 1108-1109, 2017.

[26] C. Zhu, Z. Zeng, and R. Zhao, "Adaptive suppression method for DClink voltage offset in three-phase four-switch inverter-fed PMSM drives,' Electron. Lett., vol. 52, no. 17, pp. 1442-1444, 2016.

[27] K. Ni, Y. Hu, Y. Liu, and C. Gan, "Performance analysis of a fourswitch three-phase grid-side converter with modulation simplification in a doubly-fed induction generator-based wind turbine (DFIG-WT) with different external disturbances," Energies, vol. 10, no. 5, p. 706, 2017, doi: 10.3390/en10050706.

[28] B. Lu and S. K. Sharma, "A literature review of IGBT fault diagnostic and protection methods for power inverters," IEEE Trans. Ind. Appl., vol. 45, no. 5, pp. 1770-1777, Sep. 2009.

[29] D. Ramirez and G. Venkataramanan, "Development system for wireless control applied to renewable power plants," IEEE Trans. Sustain. Energy, vol. 9, no. 3, pp. 1328-1336, Jul. 2018.

[30] Recommended Practice DNV-RP-C205, Environmental Conditions and Environmental Loads, Det Norske Veritas, Oslo, Norway, Oct. 2010.

[31] W.J. Y. Pierson and L. Moskowitz, "A proposed spectral form for fully developed wind seas based on the similarity theory of S.A. Kitaigorodskii," J. Geophys. Res., vol. 69, pp. 5181-5190, 1964.

[32] L. Moskowitz, W. J. Pierson, and E. Mehr, "Wave spectra estimated from wave records obtained by the OWS weather explorer and the OWS weather reporter," New York Univ., New York, NY, USA, Rep. no. 63-65, 1962.

[33] G. J. Komen and K. Hasselmann, "On the existence of a fully developed wind-sea spectrum," J. Phys. Oceanography, vol. 14, no. 8, pp. 1271-1285, Aug. 1984.

[34] K. Hasselmann et al., "Measurements of wind-wave growth and swell decay during the joint north sea wave project (JONSWAP)," Deutsches Hydrographisches Institut, Hamburg, Germany, 1973.

[35] D. E. Hasselmann, M. Y Dunckel, and J. A. Ewing, "Directional wave spectra observed during JONSWAP 1973," J. Phys. Ocean., vol. 11, pp. 718-728, 1980 .

[36] Y. Goda, Random Seas and Design of Maritime Structures, 3rd ed. Singapore: World Scientific, 2010.

[37] Y. Goda, "Analysis of wave grouping and spectra of long-travelled swell," Port Airport Res. Inst., Kanagawa, Japan, PARI Rep. 022-01-01, 1983

[38] E. Bouws, H. Günther, W. Rosenthal, and C. L. Vincent, "Similarity of the wind wave spectrum in finite depth water: 1 . Spectral form," J. Geophys. Res., vol. 90, no. C1, pp. 975-986, 1985.

[39] W. Mitsuyasu, "Development of spectra of wind and waves (2)," in Proc. 17th Coastal Eng. Conf., 1970, pp. 1-7.

[40] J. W. Weber and G. P. Thomas, "An investigation into the importance of the air chamber design of an oscillating water column wave energy device," in Proc. 11th Int. Offshore Polar Eng. Conf., Stavanger, Norway, 2001, pp. 17-22.

[41] A. Falcao, J. C. C. Henriques, and J. J. Candido, "Dynamic and optimization of the OWC spar buoy wave energy converter," Renewable Energy. vol. 48, pp. 369-381, 2012.

[42] W. Sheng, R. Alcorn, and A. Lewis, "Assessment of primary wave energy conversions of oscillating water columns I. Hydrodynamic analysis," $J$. Renewable Sustain. Eng.. vol. 6, 2014, Art. no. 053113.

[43] D. Zhou, J. Zhao, and Y. Liu, "Predictive torque control scheme for threephase four-switch inverter-fed induction motor drives with DC-link voltages offset suppression," IEEE Trans. Power Electron., vol. 30, no. 6, pp. 3309-3318, Jun. 2015.

[44] C. K. Lin, J. T. Yu, Y. S. Lai, H. C. Yu, and C. I. Peng, "Two-vector based modeless predictive current control for four-switch inverter-fed synchronous reluctance motors emulating the six-switch inverter operation," Electron. Lett., vol. 52, no. 14, pp. 1244-1246, 2016.

Authors' photographs and biographies not available at the time of publication. 